\title{
An experimental test of the condition dependent handicap hypothesis using Gryllus pennsylvanicus
}

by

Donovan T. Tremblay

A thesis submitted to the Faculty of Graduate and Postdoctoral

Affairs in partial fulfillment of the requirements of the degree of

Masters

in

Biology

Carleton University

Ottawa, Ontario

(C) 2019, Donovan T. Tremblay 


\section{Abstract}

Viability-based indicator models predict a positive correlation between ornamentation and longevity. Although ornament manipulations can reveal attraction and survival effects, they can inaccurately estimate the costs of ornamentation arising from correlated life-history constraints. Cotton circumvented this problem by applying a weight manipulation to stalk-eyed flies and asking whether males with bigger stalks lived longer. She found that ornamentation was positively correlated with longevity in weight manipulated males. Building upon Cotton's findings, I applied a weight and a diet manipulation to field crickets (Gryllus pennsylvanicus) and quantified their acoustic signalling and longevity. High effort signallers survived longer across all treatments. Further, males that signaled more attractively also survived longer when they experienced a weight manipulation and/or a poor diet. The weight manipulation did not directly affect longevity, because weight manipulated males dealt with the manipulation by reducing their signalling effort. Overall, my results provide support for viability-based indicator models. 


\section{Acknowledgements}

I would like to extend my gratitude to my supervisor Dr. Susan Bertram, for patiently and tirelessly assisting me with my research and writing. She has pushed me to become a better academic, a competent writer, and in general be less accident prone. Though, despite her best efforts I still find a way to injure myself weekly. Without her assistance I would not have been able to complete my thesis.

I am also grateful to the staff and faculty of the biology department at Carleton University for their assistance during my Masters. I would like to personally thank Ed Bruggink and Andras Dobai for helping with greenhouse maintenance, equipment repairs, and the occasional cricket wrangling. I would also like to thank my committee members Drs. Jean-Guy Godin and Julie Morand-Ferron for assisting with experimental design and providing constant and invaluable feedback.

I would like to extend a big thanks to all members of the Bertram lab who have made the past couple years fly by. I would like to thank Sean Neave, Daniel Gladish, Kathryn Hunt, and Michelle Leveillee for weighing hundreds of crickets and keeping them alive far longer than they wanted to. I would personally like to thank Dr. Genevieve Ferguson for allowing me to constantly pick brain about everything cricket related, for guiding me through the painful EARS analysis protocols (which I stumbled on at every step), and providing a much needed sounding board to all my problems. I would also like to thank my fellow Masters student Maria Doria for frequently reminding me about upcoming meetings, offering much needed snacks (usually mini eggs), and for always being up for a Stella at Mike's Place. Without Dr. Ferguson or Maria my past couple years would have been incredibly dull. 
The competition of my Masters thesis would not have been possible without the constant support of my friends and family. I would like to lovingly thank my fiancée, Emily Montpetit, for always supporting me, always listening to me drone on about crickets, tirelessly editing each and every draft of my thesis (even into the late hours), and for driving me to school every morning for months while my ACL healed. I would like to thank my parents, Steve and Nancy, and brother, Spencer for helping me through university and supporting me throughout my graduate studies. I would also like to thank the entirety of the Montpetits (Wally, Cathy, Sara, Angie, Dan, and Maddie) for the countless dinners out and for keeping me distracted with lively discussions of the latest and greatest fencing news.

Funding for my research was provided through research grants awarded to my supervisor, Dr. Susan Bertram, from the Natural Sciences and Engineering Research Council of Canada Discovery Grants, The Ontario Research Fund, The Carleton University Research Fund, and the Canadian Foundation for Innovation. I also received funding directly from the Department of Biology and the Graduate Students Association Travel Bursary. 


\section{Table of Contents}

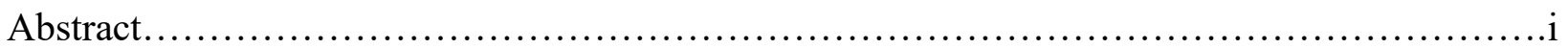

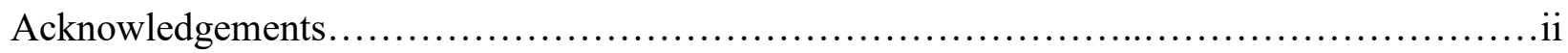

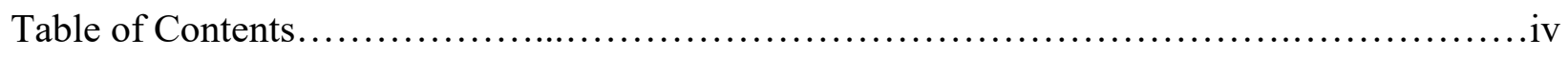

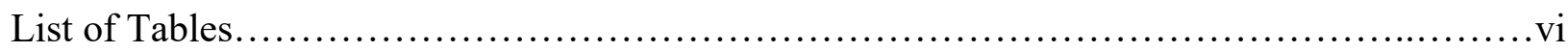

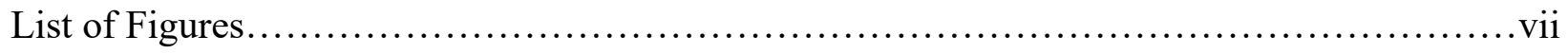

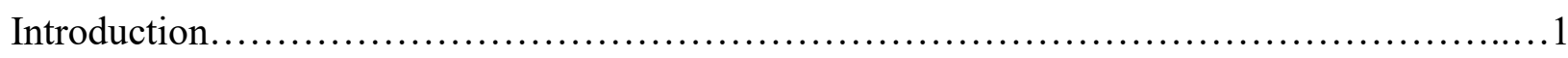

Viability-Based Indicator Models....................................................

Condition-Dependent Handicap Hypothesis........................................2

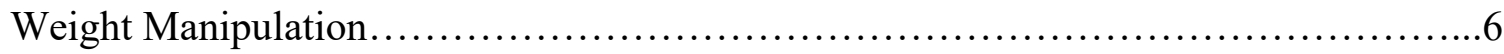

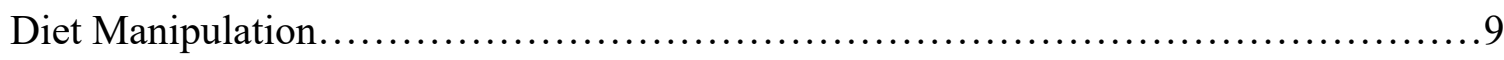

Experimental Overview.....................................................11

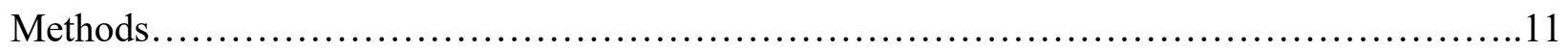

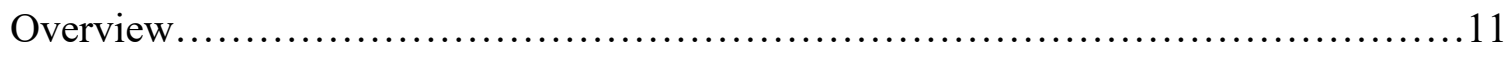

Laboratory Colony and Experimental Individuals.................................12

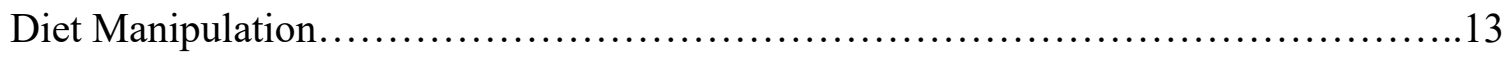

Quantifying Acoustic Signalling Behaviours....................................13

Weight and Non-Weight Treatments.............................................16 


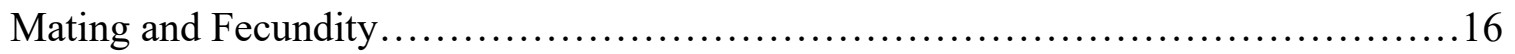

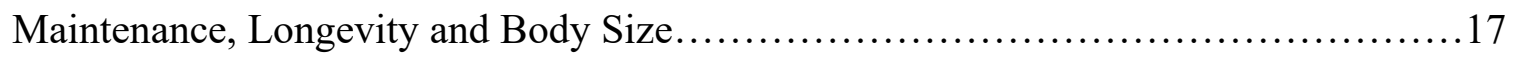

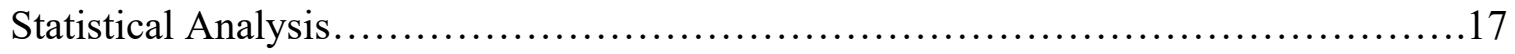

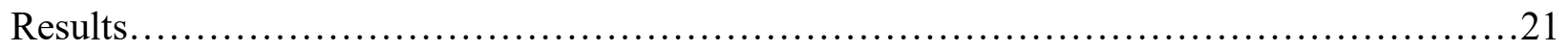

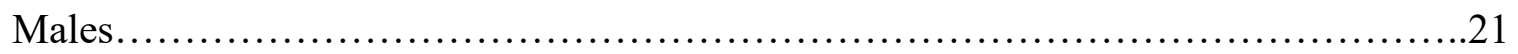

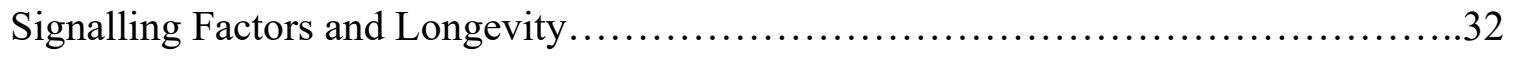

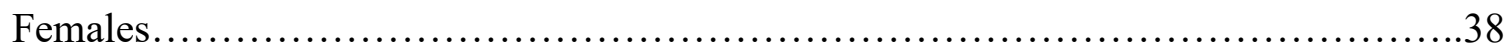

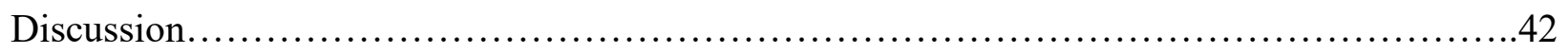

Signalling Factors and Their Interactions.......................................4

Weight Manipulation........................................................... 46

Diet Manipulation............................................................... 48

Factors Influencing Female Survival...........................................50

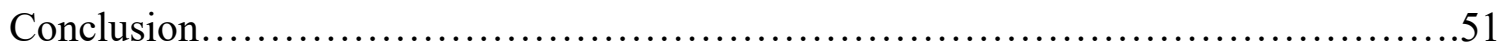

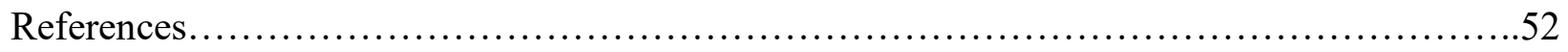




\section{$\underline{\text { List of Tables }}$}

Table 1: Factorial design and samples across both sexes and manipulations......

Table 2: Kaplain-Meier survival analysis showing how longevity is influenced by diet treatment, weight treatment, body size, time spent signalling before the addition of the weight treatment, and their interactions.

Table 3: Generalized linear model showing how signalling behaviours after the addition of the weight manipulation were influenced by diet treatment, weight treatment, body size, signalling behaviours before the addition of the weight treatment, and their interactions....

Table 4: Rotated principal components depicting fine scale signalling components signalling factors 1 and 2. A negative sign in front of a signalling component is indicative of that component being negatively associated with the related signalling factor

Table 5: Kaplain-Meier survival analysis showing how diet and weight stress treatments, signalling factors 1 and 2, and their interactions influence longevity .36

Table 6: Kaplein-Meier survival analysis using the Walds estimator testing stressors and their interactions on longevity. 


\section{List of Figures}

Figure 1: Waveform of two sequential long distance mate attraction signals (chirps) from a Gryllus pennsylvanicus displaying several parameters the Electronic Acoustic Recording System measures. Figure used with permission of Dr. Genevieve Ferguson (Ferguson, 2018).........15

Figure 2: Survival analysis showing the effect of diet and weight treatments on males..........23

Figure 3: How time spent signalling influences longevity. Results for the two diet treatments (high carbohydrate in blue and high protein in red) are shown...........................24

Figure 4: Time spent signalling one week before the weight was applied (unshaded section) and one week after the weight stress was added (shaded section). Error bars represent standard

error. .26

Figure 5: Influence of signalling behaviours before the addition of the weight treatment, diet treatment, and weight treatment on the signalling behaviours after the addition of the weight treatment. .28

Figure 6: Fluctuations in amplitude one week before (white) and after (shaded blue) a weight stressor was applied across all treatments.

Figure 7: Fluctuations in carrier frequency one week before (white) and after (shaded blue) a weight stressor was applied across all treatments.

Figure 8: Relationship between the signal factor 2 and time spent calling before the addition of

the weight.

Figure 9: Relationship between signalling factor 2 and survival post eclosion across both diet and weight treatments. 
Figure 10: Plotted Kaplain-Meier survival analysis showing the impact of diet and weight stress, across high carbohydrate and high protein diets, on longevity in females...................40

Figure 11: Relationship between the number of eggs an individual oviposited in one week and its impact on longevity across the different weight and diet stress treatments...................41 


\section{$\underline{\text { Introduction }}$}

When Charles Darwin published the Descent of Man and Selection in Relation to Sex in 1871 , his theory of sexual selection was met with trepidation. He described exaggerated secondary sexual traits as weaponry or ornaments and proposed that males could use these exaggerated traits to enhance their mating success by: (1) competing with other males for access to females (e.g., intrasexual selection or male-male competition), and/or (2) enticing females to mate (e.g., intersexual selection or female mate choice; Darwin, 1859; Darwin, 1871). The scientific community largely initially rejected Darwin's second idea, that females exhibit mating preferences for male exaggerated ornaments (Pomiankowski, 1988; Andersson, 1994), until Fisher proposed his theory of runaway sexual selection in 1930.

\section{Viability-Based Indicator Models}

Fisher (1930) proposed that females could gain fitness benefits by choosing to mate with males displaying highly exaggerated ornaments, as highly exaggerated traits should initially signal higher male fitness. Provided ornaments and preferences have a genetic basis, selectively mating with males displaying highly exaggerated ornaments should result in offspring with higher fitness (daughters with stronger preferences and sons with highly exaggerated ornaments) (Fisher, 1930; Lande, 1981). Fisher (1930) assumed a genetic correlation existed between male ornaments and female preferences. Fisher (1930) suggested that if female preferences were strong enough, they should be able to override the natural selection acting on the exaggerated ornaments, even when the exaggerated ornaments had become detrimental to survival. Fisher (1930) proposed that over multiple generations a positive feedback loop would result in female mating preferences for elaborate ornamental traits that do not provide fitness benefits. 
Fisher's (1930) idea that runaway selection provides the mechanism for evolution of female mate choice was problematic because strong mate choice for exaggerated ornaments should erode genetic diversity. Why should females continue to exhibit preferences for males with elaborate ornaments once there is no variation in loci associated with either ornamentation or viability to enhance offspring fitness (Kotiaho et al. 2008)? To solve this conundrum, Zahavi $(1975,1977)$ proposed that elaborate ornaments evolved simply because they are costly to produce and maintain. Females could use ornament elaboration as an indicator of male quality. Zahavi $(1975,1977)$ predicted that females should be selected to mate with high quality males to increase their offspring's chances of survival and future reproductive success.

\section{Condition-Dependent Handicap Hypothesis}

Zahavi proposed three separate hypotheses to account for the evolution of elaborate male ornaments and female preferences: the handicap hypothesis, the revealing hypothesis, and the condition dependent handicap hypothesis (Zahavi, 1975; Zahavi, 1977). Here I focus on the condition dependent handicap hypothesis, which states that the degree of ornament exaggeration is proportional to the condition of the male. Males in good condition should have more exaggerated ornamentation and increased viability (Zahavi, 1977; Cotton et al., 2004). Iwasa and Pomiankowski (1994) modelled and supported Zahavi's ideas outlining female preference, male viability, and the costs associated with the male's ornament. Grafen (1990) utilized a game theory model to determine whether the condition dependent handicap hypothesis could be explained without a runaway mechanism. Grafen (1990) found that the costs of ornaments were related to the overall condition of the male and did not require a runaway process. Both Grafen (1990) and Iwasa and Pomiankowski $(1994,1999)$ found support for the condition dependent handicap hypothesis, provided the ornaments are honest indicators of male viability (Grafen 
1990; Iwasa and Pomiankowski, 1994; 1999). Cotton et al. (2004) conducted a meta-analysis revealed that ornaments demonstrate heightened condition dependent expression (Cotton et al. 2004). Together these studies suggest both theoretical and empirical support for the condition dependent handicap hypothesis.

Many researchers have used manipulations to experimentally test the condition dependent handicap hypothesis. For example, Andersson (1982) examined female choice in the Widowbird by physically manipulating the length of males' tail feathers. Andersson found that the degree of ornamentation mattered. Males with tail feathers that were artificially lengthen mated more often than males with shortened tail feathers. Møller (1989) found that male barn swallows with experimentally lengthened tails were more attractive and had an increased mating success compared to males that possessed experimentally shortened tails. Bachanan and Evans (2000) hypothesized that barn swallows developed larger tail feathers to increase their aerodynamics at high speeds, thereby evolving through natural, not sexual selection. Bachanan and Evans (2000) tested their alternative hypothesis using 3D mapping and slow-motion video analysis to view flight patterns. Interestingly, they found that tail feathers had exceeded optimum aerodynamic length by approximately $10 \mathrm{~mm}$; they concluded that the tail lengths were influenced by both natural and sexual selection, as their findings supported both the aerodynamic and condition dependent handicap hypotheses. Further, Balmford et al. (1994) performed a meta-analysis comparing wing and tail lengths in 57 bird species and found that species with more elaborate tail ornaments possessed longer wings that allowed them to bare the aerodynamic costs of being ornamented with extravagant tails. Together, these experimental and phylogenetic studies suggest support for the condition dependent handicap hypothesis. 
Research on the condition dependent handicap hypothesis has not been limited to birds. Cabrera-Guzmán et al. (2013) examined whether body size was related to viability in cane toads. Individuals with a larger body size at metamorphosis had enhanced survival, growth, and performance. Size at metamorphosis is highly plastic and can be affected by conspecific density and environmental conditions. Cabrera-Guzmán et al. (2013) found that individuals that metamorphosed at a larger size were better at catching and consuming prey, and better at locomotion. As a result, cane toads with a larger body size also possessed increased viability, suggesting further support for the condition dependent hypothesis.

Several invertebrate studies also support the condition dependent handicap hypothesis. Unfortunately, researchers can rarely directly manipulate the invertebrate's exaggerated ornament without premature and immediate death. Therefore, to test the condition dependent handicap hypothesis, researchers instead conducted phylogenetic analyses, meta-analyses, or indirectly manipulated ornaments using dietary manipulations. For example, Baker and Wilkinson (2001) performed a phylogenetic analysis of sexual dimorphism in the stalk-eyed fly. They showed that there was a positive relationship between eye-stalks and body size and that females were actively selecting upon stalk-eyed length. Baker and Wilkinson (2001) revealed that there is an evolutionary pattern in eye span allometry that is influenced by phylogeny more than morphology, consistent with the prediction of strong sexual selection on ornamental traits. Further Burkardt and Motte (1985) performed research on viability based on available resources in stalk-eyed flies. They found ongoing changes in sexual dimorphism resulting from variation in the available resources during the larval stage, which resulted in high variation in eye span.

Holzer et al. (2003) investigated the relationship between nutrition and quality in field crickets and found a positive relationship between food availability, body condition, and male 
acoustic sexual displays. Previous research had failed to show how resource allocation interacts with body maintenance, reserves, and sexually selected traits under normal conditions. To get around this problem Holzer et al. (2003) investigated the influence of food availability on body condition, acoustic mate attraction signalling (calling behaviour), and sexual attractiveness of crickets in nature by manipulating their food supply. Males who had access to more food showed increased body condition and increased time spent calling, but did not alter the other characteristics of their acoustic mate attraction displays. Importantly, males who had access to more food also attracted more mates. Scheuber et al. (2003a) also investigated condition dependence of sexual signals by manipulating available food sources in crickets. Males that were given a larger food supply increased their calling and chirp rates, and decreased their interchirp duration. Scheuber et al. (2003b) also manipulated the diets of nymphs to assess adult signalling behaviour. Restricted diets caused individuals to develop slower and to be smaller at adulthood. Scheuber et al. (2003b) found a positive relationship between body size and harp size, and showed that chirp rate was an indicator of male quality.

Although the aforementioned studies reveal support of the condition dependent handicap hypothesis, they often fail to compare condition dependence in sexual ornaments with nonsexual traits (Cotton et al. 2004). Previous work relied heavily on ornament manipulation and how it influences survival, but this fails to account for the fitness consequences of correlated life history traits (Cotton, 2016). Previous experimental work has also often utilized extreme stress manipulations rather than using stress manipulations akin to what is expected in nature. Further, results from manipulative studies that alter the exaggerated secondary organs have the potential to misrepresent the results. For instance, if researchers manipulate the horns of the Hercules beetle, reducing the size of the horn should decrease mating success. This reduced mating 
success may cause males to alter the allocation of energy from reproductive efforts and reallocate this energy into survival. If this were to happen, even though males may have reduced reproductive rates, their prolonged life could result in higher lifetime viability. The opposite might occur if horn size were to be increased, as it might increase the amount of stress resulting in premature mortality. Males might therefore experience a short-term increase in reproductive success coupled with a decrease in survival.

\section{Weight Manipulation}

To circumvent these concerns, Alison Cotton (2016) completed one of the most novel tests of the condition dependent handicap hypothesis to date. For her PhD thesis, Cotton (2016) subjected stalk-eyed flies to increased weight stress instead of manipulating their elaborate ornamentation. Cotton (2016) ran two complementary experiments, one in the field and the other in the lab. In both experiments she glued small weights onto the back of the stalk-eyed flies to increase the weight that the individuals had to carry during flight. Cotton (2016) found that individuals with added weight died sooner than individuals without. In support of the condition dependent handicap hypothesis, she showed that males with added weight who had relatively larger eye spans survived longer than males with added weight and relatively smaller eye spans. Longevity was not explained by eye span in control males who did not bear the added cost of the weight. Cotton used females as an additional internal control because they lack the ornamentation that they use to select upon mates. Cotton (2016) found that female eye span did not impact longevity, regardless of whether the females were weighted or not. Together these findings provide experimental support for the condition dependent handicap hypothesis.

For my MSc thesis, I conducted a similar experiment to Cotton's (2016) study to test the condition dependent handicap hypothesis. I used the fall field cricket, Gryllus pennsylvanicus, as 
my model organism because the factors influencing mating success have been well documented. Males exhibit extensive repeatable variation in their acoustic mate attraction signalling behaviour (Harrison et al. 2013). These mating signals may relay information about male quality. For example, Judge et al. (2011) found a correlation between body size and carrier frequency, with larger males signalling with lower carrier frequencies. Females appear to be able to utilize the information contained in male acoustic mate attraction signals in mate choice, as males that signal most often, loudest, and with lower carrier frequencies usually have the highest mating success (Jeffery et al. 2005; Judge, 2011). Further, females preferentially mate with males that signal most often, loudest and with lower carrier frequencies (French and Cade, 1989; Judge, 2011). Given females exhibit preferences for males that signal more elaborately, field crickets are a good model organism for investigating whether there is support for the condition dependent handicap hypothesis.

The sexual signals male crickets produce may benefit them through sexual selection, but they can also incur costs through natural selection. These conspicuous signals can be considered a handicap because they are energetically costly to produce (Scheuber et al 2003a; Mowles 2004) and can increase the risk of parasitism and predation (Roberts et al 2006; Beckers and Wagner 2012). Mowles (2004) examined the energetic costs of signalling in Gryllus bimaculatus and found that levels of haemolymph lactate increased in concentration after signalling relative to the control. Those males who signalled at a higher rate had higher concentrations of haemolymph lactate. Mowles (2004) supported the notion that signalling was metabolically costly. Bertram (2004) examined the signalling patterns of male Gryllus texensis. Males exhibited diel shifts based on expected presence of females and parasitoid flies. When parasitoid flies were most 
abundant males refrained from signalling and when females were most abundant males signalled (Bertram et al 2004).

I hypothesized that the addition of weights to the thorax (weight manipulation) should impact longevity. I predicted that males and females who experience a $20 \%$ increase in body weight (weight manipulation treatment) would die sooner than the control (non-weighted treatment) individuals. I also predicted that weighted females would produce fewer eggs and weighted males would decrease their signalling behaviours compared to control (non-weighted) individuals. To test the condition dependent handicap hypothesis, I hypothesized that males with more elaborate secondary sexual traits would be better able to handle the weight manipulation compared to males with less elaborate secondary sexual traits. Specifically, I predicted that: larger weighted males should survive longer than smaller weighted males; weighted males with more elaborate acoustic mate attraction signals (louder, lower carrier frequency, and higher chirp rate) should survive longer than weighted males with less elaborate signals; and males that signaled with higher effort (higher time spent calling) before the addition of the added weight would survive longer than males that signalled with lower effort.

Cotton's (2016) weight manipulation had a profound effect on fly survival. This is not surprising, given stalk-eyed flies rely mostly on flight to move from one location to the next. Any added weight should dramatically increase the energy required for their flight, and as a result reduce the energy available for other tasks, such as body maintenance. However, I was unsure whether a $20 \%$ addition of weight would have a profound effect on cricket longevity, given crickets walk much more often than they fly. The energetic costs of carrying an extra $20 \%$ of body weight for walking are likely to be a lot less than carrying an extra $20 \%$ of body weight while flying. I was therefore uncertain whether a weight manipulation would impact longevity in 
field crickets. To circumvent this problem, I decided to also use a diet manipulation to impact cricket longevity.

\section{Diet Manipulation}

The quality and quantity of the diet can profoundly impact an animal's fitness (Sterner and Elser, 2002). Most previous research has focused on simplistic nutrient measures that have either varied the quantity or quality of food an individual receives by altering the amount of different nutrient dense foods (Harrison et al. 2017). However, different nutrients play different roles in how they affect an individual's growth, development, elaborate sexually selected trait expression, reproduction, and survival (Harrison et al. 2017). It is therefore important to carefully determine the importance of different nutrients, because the availability of different macronutrients can resonate through physiological and behavioural traits. A nutritional geometric approach allows researchers to examine the relationship between different macronutrients such as protein and carbohydrates and how they each effect a variety of life history traits.

Field crickets are ideal model organisms for nutritional geometric manipulations, because they are omnivorous and feed on a variety of plants and insects, each with differing nutritional compositions (Criddle, 1925; Gangwere, 1961; Joern and Behmer, 1997; Carmona et al. 1999), so they are apt to experience a wide variety of macronutrient availability in nature. Further, the impact of different carbohydrate to protein ratios in the crickets' diet have been largely been determined. We know that proteins are important for juvenile cricket development because they are fundament for tissue and muscle growth, whereas carbohydrates provide they energy required for crickets to move, fly, and signal acoustically for mates (Holzer et al. 2003; Maklakov et al. 2008; Thomson et al. 2014; Reifer et al. 2018). Reifer et al. (2018) showed that 
field crickets reared on high protein diets developed faster and were larger at adulthood than crickets reared on high carbohydrate diets. Maklakov et al. (2008) and Harrison et al. (2014) found that male and female cricket longevity was maximized when individuals consumed high carbohydrate diets compared to high protein diets. Conversely, Harrison et al. (2014) showed that female reproductive performance (number of eggs oviposited) was maximized on a high protein diet compared to a high carbohydrate diet. Maklakov et al. (2008) showed that male reproductive performance was maximized on a high carbohydrate diet, possibly because prolonged signalling burns carbohydrates (Thomson et al. 2014). Harrison et al. (2014) also found males fed either a high carbohydrate or balanced diet showed an overall increase in mate signalling behaviour when compared to males reared on high protein diets. Further, Reifer et al. (2018) showed that males that experienced a switch from high protein diet during development to high carbohydrate diet during adulthood signalled most often and produced the most attractive mating signals (Reifer et al. 2018).

Given the impact nutrient availability has on cricket reproduction and survival, I hypothesized that the availability of carbohydrates and protein in the diet would impact life history traits and longevity, and the effects would be sex specific. Based on the aforementioned studies, I predicted that males fed the high carbohydrate diet during adulthood would live longer and signal with higher effort compared to males fed the high protein diet. Conversely, I predicted that females would experience a trade-off between reproductive success and longevity. Specifically, females fed the high protein diet would produce more eggs but die sooner than females fed the high carbohydrate diet. 


\section{Experimental Overview}

I employed a fully factorial design using weight and diet treatments to manipulate longevity in male and female G. pennsylvanicus. Starting at adulthood, I fed individuals either a high protein or high carbohydrate diet and then quantified male acoustic mate attraction signaling behaviour for a one-week period. I then added a $20 \%$ weight manipulation to half of the individuals on each diet. I quantified male signalling behaviour and female egg laying for a one-week period and then monitored all experimental individuals until they died a natural death. I asked how these diet and weight treatments impacted signalling behaviour, egg laying behaviour, and survival. To test the condition dependent handicap hypothesis, I asked whether males with more elaborate signals were able to better afford the costs of these weight and diet stressors to survive longer than males with less elaborate signals.

\section{$\underline{\text { Methods }}$}

Overview

I housed newly eclosed experimental males and females individually with their food, water, and shelter for a one-week period (Days 1-7 of adulthood; details provided in the Laboratory Colony and Experimental Individuals section, below). I then moved each individual into the Electronic Acoustic Recording system (EARs) to quantify male acoustic mate attraction signalling behaviour for a one-week period (Days 7-14; details provided in the Quantifying Acoustic Signalling Behaviours section, below). I then assigned each experimental individual to a weighted treatment or a non weighted (control) treatment (Day 14) and applied the weight or wax (control) (details provided in the Weight Treatment section, below). I re-quantified male acoustic mate signalling behaviour for a further one-week period (Days 14-21). Both males and 
females were then mated. I allowed females to lay eggs for a one-week period to quantify their fecundity (Days 14 - 21; see Mating and Fecundity, below). I monitored all experimental individuals daily until they died a natural death. At that time, I froze their bodies for subsequent body size analysis (see the section on Maintenance, Longevity and Body Size, below).

\section{Laboratory Colony and Experimental Individuals}

I obtained all of my experimental individuals from a laboratory reared colony of North American Fall Field Crickets, Gryllus pennsylvanicus. The laboratory colony was established in 2010 through a founding population of several hundred adults that were collected at Jokers Hill (Keffler Scientific Reserve of the University of Toronto, located in Oak Ridge Morain, Ontario). Since 2010 , we have added $\sim 50$ adult individuals annually to the population to maintain genetic diversity. These adults were collected at Carleton University's campus and from the surrounding area. Further, I added $\sim 50$ newly collected adult individuals to the laboratory reared colony just prior to the start of my experiments.

The laboratory colony was housed in large plastic containers $(64 \times 40 \times 42 \mathrm{~cm})$ inside a temperature $\left(26 \pm 2^{\circ} \mathrm{C}\right)$ and photoperiod $(14: 10$ hour light:dark cycle) controlled greenhouse. Crickets were provided with moist sand for egg laying, a standard diet (Harlan Tekland Inc. Rodent diet \# 860414) for food, water, and shelter (stacked cardboard egg cartons).

I removed males and females from the rearing colony bins as soon as they developed visible wing buds, as this was the time that I could visually distinguish males from females. I separated males from females and placed each sex into large plastic segregated sex rearing containers $(64 \times 40 \times 42 \mathrm{~cm})$, thereby ensuring experimental individuals were virgins at adulthood. I kept these segregated sex rearing containers at a constant density of 10 juveniles per 
bin. I checked the individuals in each sex segregated rearing container three times a week (Monday, Wednesday, and Friday) to see whether any had either died or moulted to adulthood. I replaced dead individuals and individuals that had moulted to adulthood with juveniles (wing buds visible) of the same sex from the laboratory colony to ensure the sex segregated rearing containers maintained a constant density. Individuals in these sex segregated bins were provided with food, water, and shelter and were retained under the same temperature and photoperiod regime in the greenhouse as described above.

I removed all newly eclosed adults (hereafter Day 1 post imaginal moult) from the sex segregated rearing containers, weighed them (OHAUS Pioneer Analytical Balance Model: Adventurer SL AS64; $\mathrm{d}=0.0001 \mathrm{~g}$ ) and placed each individual into its own container (500 ml; $12.5 \times 8.5 \times 7.5 \mathrm{~cm})$. These individuals became my experimental individuals.

\section{Diet Manipulation}

I assigned each newly moulted adult experimental individual to either a high carbohydrate diet (1:3 protein:carbohydrate) or a high protein diet (3:1 protein:carbohydrate) using a random number generator. I created the diets followed protocols established by Harrison et al (2014). Briefly, the proteins in the diets were composed of varying quantities of cellulose, casein, albumen, and peptones. The carbohydrates in the diets were comprised of sucrose and dextrin. Both high protein and high carbohydrate diets contained the exact same quantities of other required micronutrients and lipids.

\section{Quantifying Acoustic Signalling Behaviours}

When individuals reached 7 days post imaginal moult, I placed them into the Electronic Acoustic Recording System (EARS) for two consecutive one-week periods (Days 7-14 and 14- 
21 post imaginal moult). I placed each individual (within its $500 \mathrm{~mL}$ container) into a Styrofoam cooler box ( $5.08 \mathrm{~cm}$ thick Styrofoam) that had been lined with acoustically insulating foam (2.54 $\mathrm{cm}$ inch thick acoustic foam). The underside of the lid of the box was comprised of a microphone and a LED light (14:10 hour light : dark cycle). The microphone recorded the signalling behaviours using the CricketSong software (Cambridge Electronic Design Cambridge, United Kingdom), which filtered out and eliminated background noise. The EARS allowed me to quantify male acoustic mate attraction signalling behaviours including: pulse duration, interpulse duration, chirp duration, interchirp duration, pulses per chirp, pulse rate, chirp rate, dominant frequency, amplitude, and time spent calling/day (Figure 1). To ensures females were treated in an identical manner to males, I kept each of the experimental females in the EARS as well, even though they do not signal acoustically. 


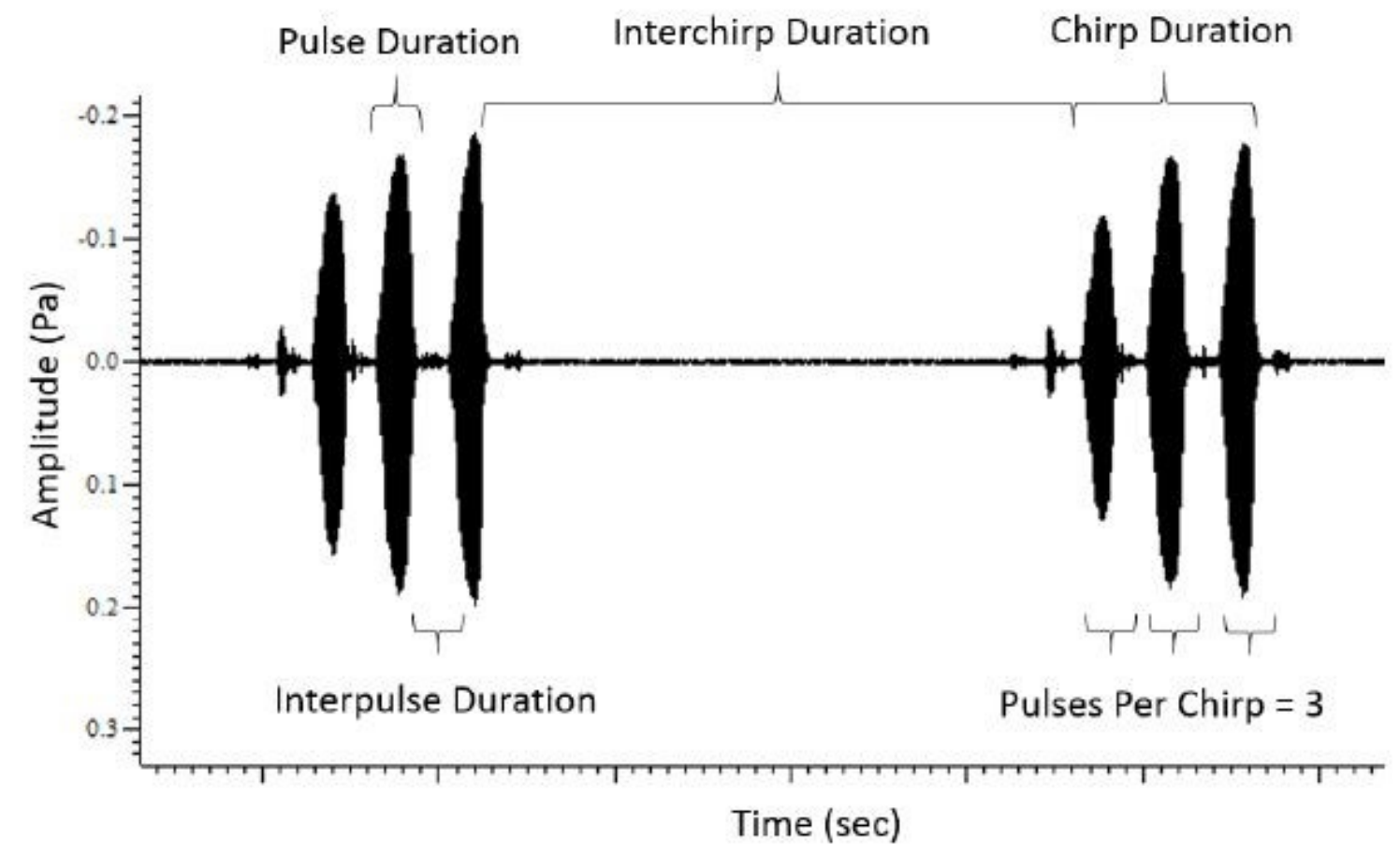

Figure 1: Waveform of two sequential long distance mate attraction signals (chirps) from a Gryllus pennsylvanicus displaying several parameters the Electronic Acoustic Recording System measures. Figure used with permission of Dr. Genevieve Ferguson (Ferguson, 2018) 


\section{Weight and Non-Weight Treatments}

On Day 14 post imaginal moult, I removed each individual from the EARS and reweighed it. Using a random number generator, I assigned half of the individuals from each diet treatment to a weighted treatment, and the other half to the non weighted (control) treatment. All individuals assigned to the weighted treatment received a tailored weight that was $20 \%$ of their body weight ( $\pm 2 \mathrm{mg}$ ). I created each weight out of solder containing $97 \%$ tin and $3 \%$ copper (Lenox lead-free solder: WS15064). I cut the solder into small 3 to $5 \mathrm{~mm}$ segments, flattened them, and then crimped them into thin strips. I then dipped these strips into liquid wax (Parissa Hot Wax) and weighed each strip again to ensure that it weighed $20 \%$ of the body weight of the individual that I was tailoring it for. I reheated the wax to adhere the tailored weight to the pronotum of the individual. All individuals assigned to the non weighted treatment were handled in the same way, with the exception that to each I only adhered a drop of hot wax (Parissa Hot Wax) to their pronotum. All individuals were placed back into the EARS, and males had their acoustic mate attraction signals monitored for an additional 7 days.

\section{Mating and Fecundity}

At Day 15 post imaginal moult, I mated each experimental individual to a nonexperimental individual from the laboratory reared colony. Colony individuals were weighed prior to being placed with the experimental individuals. Mates were removed one day after mating (Day 16 post imaginal moult). I provided a small cup of wet sand to the experimental female containers for egg laying. I allowed females to oviposit eggs for a one-week period (Days 14-21 post imaginal moult), after which I removed the cup, and counted the eggs. 
Maintenance, Longevity and Body Size

Food and water were replenished thrice weekly on a Monday, Wednesday, and Friday schedule. I also ensured that each experimental individual's weight and/or wax was still attached. If the weight and/or wax had become detached, I immediately reattached it. I watered the sand I provided to the females for egg oviposition on this thrice weekly schedule. At 21 days post imaginal moult, I reweighed each experimental female and moved it out of the EARs and back into the colony greenhouse. Females had their sand cups removed and their eggs counted. All experimental individuals were held in their individual containers in the greenhouse for the remainder of their lives. Food and water were provided ad libitum. When an individual died, I recorded its date of death and then froze it for subsequent morphometric analysis. To quantify body size, I placed individuals dorsal side up next to a ruler and then photographed them (Lumix Panasonic Camera) at $0.2 \mathrm{x}$ zoom. I used ImageJ to quantify the maximum distance between the eyes.

Statistical Analysis

I ran Kaplain-Meier survival analyses on both males and females ( $\mathrm{N}=465$ across 8 treatments; Table 1). I examined how male survival (dependent variable) was impacted by the following independent variables: diet treatment (carbohydrate or protein rich), weight treatment (weighted versus non weighted control), time spent signalling before the addition of the weight manipulation, residuals of the time spent signalling after the addition of the weight manipulation, body size, and all possible interactions between diet treatment, weight treatment, and time spent signalling before the addition of the weight. The largest interaction that I used was the three-way interaction between diet manipulation, weight manipulation, and time spent signalling before the addition of the weight manipulation. I used model simplification techniques to remove non- 
significant interactions and note that there was no difference in significant variables between the simplified and full models, I therefore used the full model.

I ran a generalized linear model to determine if males altered their signaling behaviours after the addition of the weight. I examined how time spent signalling after the addition of the weight (dependent variable) was influenced by the following independent variables: time spent signalling before the addition of the weight, diet and weight manipulations, and body size. I included interactions between time spent signalling, diet manipulation, and weight manipulation. The three-way interaction between time spent signalling, diet manipulation, and weight manipulation, was the largest interaction in my model. I used model simplification techniques to remove non-significant interactions; there was no difference in significant variables between the simplified and full models, therefore I used the full model.

The fine scale parameters of male acoustic mate attraction signals that often influence female mate choice include amplitude, carrier frequency, chirp rate, and body size (Jeffery et al. 2005; Judge, 2011). To investigate whether these aforementioned traits that appear to influence male attractiveness were impacted by diet and/or weight treatment, I ran a principle component analysis (PCA) with factor rotation. Two factors explained $73 \%$ of the variation in carrier frequency, amplitude, chirp rate, and body size. I investigated whether these factors were related to signalling effort. I also investigated whether survival was influenced by either of these signalling factors and the residuals of time individuals spent calling in their second week. I included possible interactions. The largest interactions I included in this model were diet manipulation, weight manipulation and signalling factor 1 , and another including diet manipulation, weight manipulation and signalling factor 2. Removing non-significant interactions from the model did not alter my results, therefore I used the full model. 
For the females, I examined how survival (dependent variable) was impacted by the following independent variables: diet treatment (carbohydrate versus protein rich), their weight treatment (weighted versus non weighted control), their fecundity (number of eggs oviposited), and all possible interactions. The largest interaction included in my model was between diet treatment, weight treatment, and fecundity. After using model simplification by removing nonsignificant interactions, I found there was no difference between simplified and full models. I therefore used the full model. 
Table 1: Factorial design and samples across both sexes and manipulations

\begin{tabular}{|c|c|c|}
\hline Female & Weighted & $\begin{array}{c}\text { Non- } \\
\text { Weighted } \\
\text { (Control) }\end{array}$ \\
\hline $\begin{array}{l}\text { High } \\
\text { Carbohydrate } \\
\text { Diet }\end{array}$ & 61 & 60 \\
\hline $\begin{array}{l}\text { High } \\
\text { Protein } \\
\text { Diet }\end{array}$ & 60 & 60 \\
\hline
\end{tabular}

\begin{tabular}{|l|c|c|}
\cline { 2 - 3 } \multicolumn{1}{l|}{ Male } & Weighted & $\begin{array}{c}\text { Non-Weighted } \\
\text { (Control) }\end{array}$ \\
\hline $\begin{array}{l}\text { High } \\
\text { Carbohydrate } \\
\text { Diet }\end{array}$ & 60 & 57 \\
\hline $\begin{array}{l}\text { High } \\
\text { Protein } \\
\text { Diet }\end{array}$ & 58 & 58 \\
\hline
\end{tabular}




\section{$\underline{\text { Results }}$}

Males

Male survival was impacted by diet (Table 2; Figure 2). Specifically, males who consumed a carbohydrate rich diet during adulthood lived significantly longer than males who a consumed protein rich diet (average $=51$ days versus 40 days, respectively). Male survival was also influenced by time spent calling before the addition of the weight manipulation (Table 2; Figure 3). Males that spent more time signalling for mates lived significantly longer than males that spent less time signalling for mates. Weight treatment, body size, and all the interactions did not significantly influence male longevity (Table 2). 
Table 2: Kaplain-Meier survival analysis showing how longevity is influenced by diet treatment, weight treatment, body size, time spent signalling before the addition of the weight treatment, and their interactions.

\begin{tabular}{l} 
Source \\
\hline Diet \\
Weight \\
Diet * Weight \\
Time Spent Signalling Before \\
Diet * Time Spent Signalling Before \\
Weight * Time Spent Signalling Before \\
Diet * Weight * Time Spent Signalling Before \\
Body Size \\
Residuals of Time Spent Signalling After
\end{tabular}

Wald ChiSquare Prob $>$ ChiSq 23.4312 $<0.0001$

$0.0568 \quad 0.8117$

$0.0002 \quad 0.9876$

$\begin{array}{ll}4.6147 & \mathbf{0 . 0 3 1 7}\end{array}$

$0.1467 \quad 0.7071$

2.4177

0.1200

2.5045

0.1135

0.7759

0.3784

1.9754

0.1599 


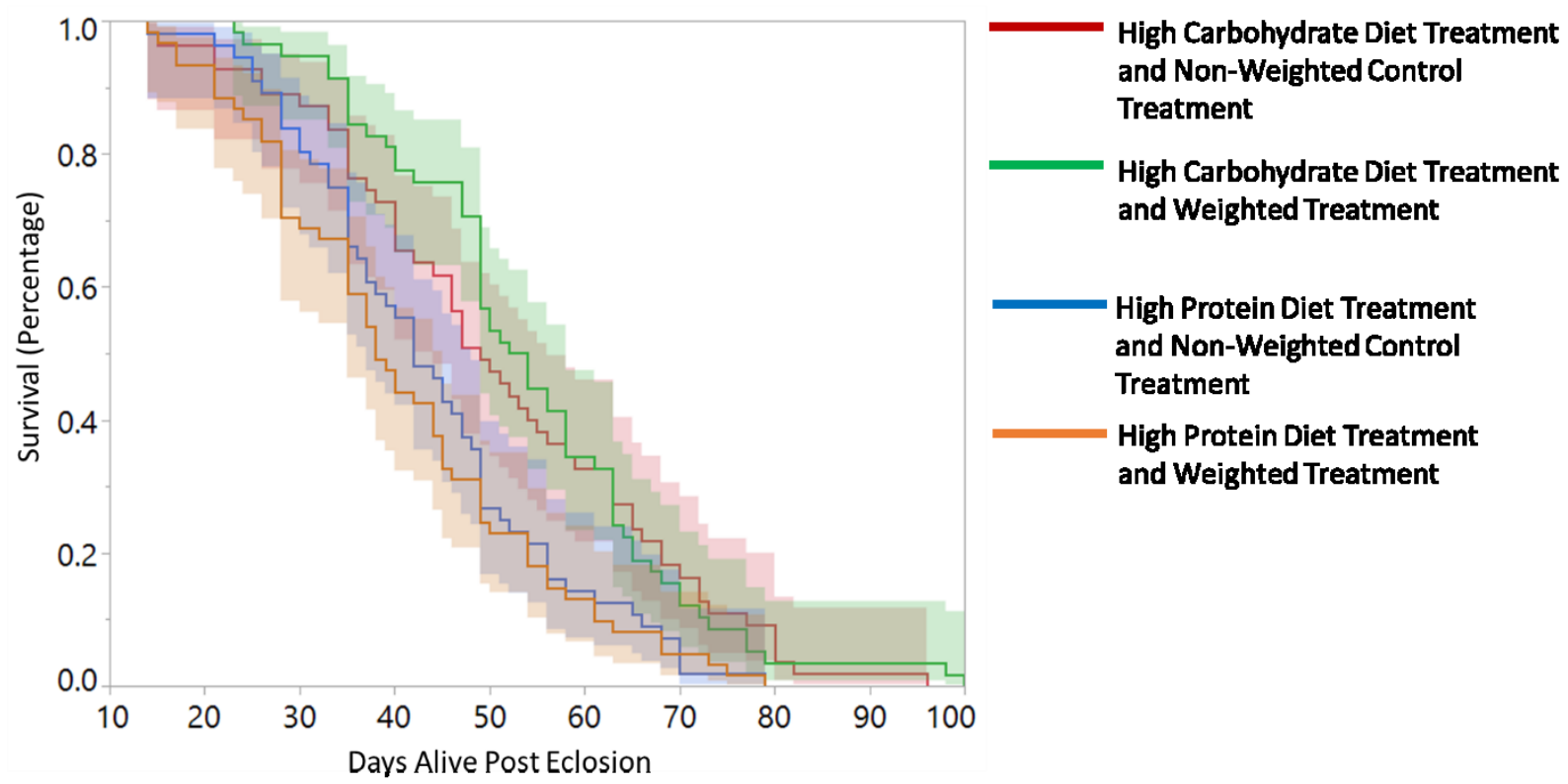

Figure 2: Survival analysis showing the effect of diet and weight treatments on males. 


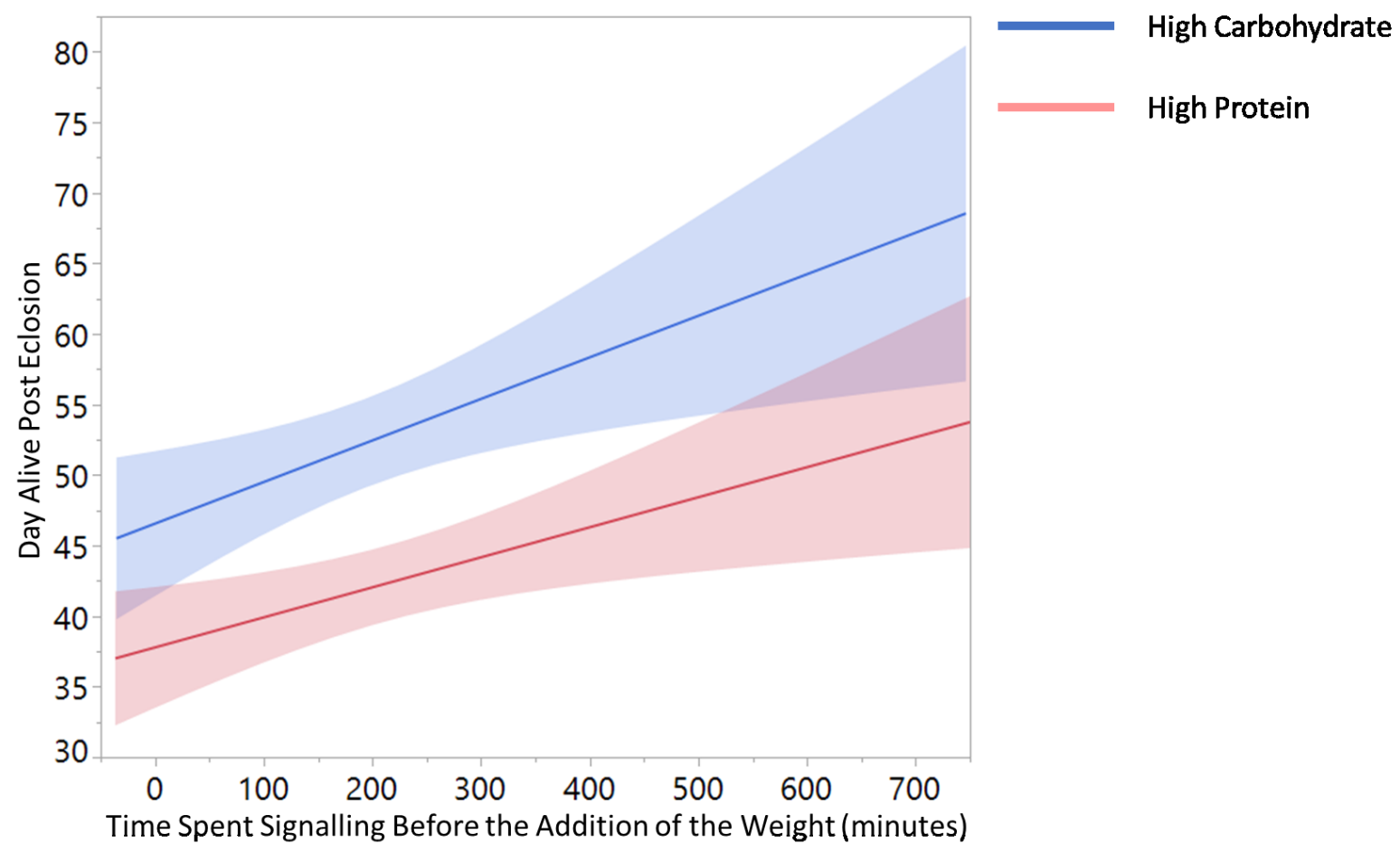

Figure 3: How time spent signalling influences longevity. Results for the two diet treatments (high carbohydrate in blue and high protein in red) are shown. 
Males altered their signalling efforts over time. Specifically, males reduced their signalling effort when they were 14-21 days post eclosion, compared to when they were 7-14 days post eclosion (Figure 4). Interestingly, males who experienced the $20 \%$ addition of the body weight reduced their signalling effort significantly more than the control males (Table 3; Figure 5). Further, this reduction in signalling effort of the weighted males was most pronounced in the individuals that consumed the high protein diet (Figure 5; Table 3). That said, males who spent more time signalling before the addition of the weight also spent relatively more time signalling after the addition of the weight (Figure 5; Table 3). There was an interesting significant interaction between the weight manipulation and time spent signalling before the addition of the weight manipulation. Males with high time spent signalling before the addition of the weight reduced their signalling effort more after they had the weight glued on them than males with low time spent signalling. 


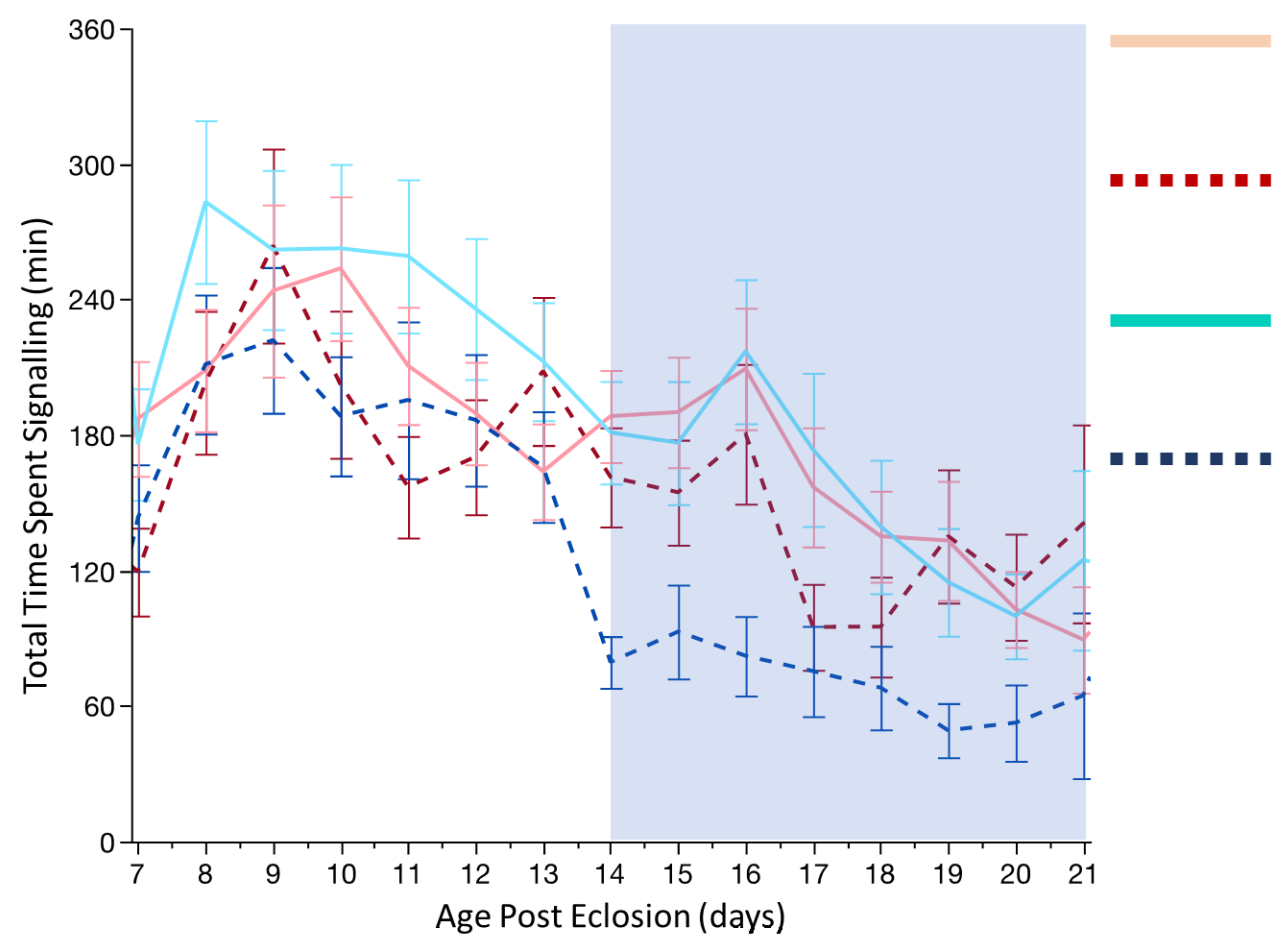

High Carbohydrate Diet Treatment and Non-Weighted Control Treatment

High Carbohydrate Diet Treatment And Weighted Treatment

High Protein Diet Treatment and Non-Weighted Control Treatment

High Protein Diet Treatment and Weighted Treatment

Figure 4: Time spent signalling one week before the weight was applied (unshaded section) and one week after the weight stress was added (shaded section). Error bars represent standard error. 
Table 3: Generalized linear model showing how signalling behaviours after the addition of the weight manipulation were influenced by diet treatment, weight treatment, body size, signalling behaviours before the addition of the weight treatment, and their interactions.

\begin{tabular}{l|rr} 
Source & ChiSquare & Prob>ChiSq \\
\hline Diet & $\mathbf{8 . 7 4 7 7}$ & $\mathbf{0 . 0 0 3 1}$ \\
Weight & $\mathbf{9 . 7 2 7 9}$ & $\mathbf{0 . 0 0 1 8}$ \\
Diet* Weight & 1.9673 & 0.1607 \\
Time Spent Signalling Before & $\mathbf{7 7 . 4 3 8 7}$ & $<\mathbf{0 . 0 0 0 1}$ \\
Diet * Time Spent Signalling Before & 2.8103 & 0.0937 \\
Weight * Time Spent Signalling Before & $\mathbf{1 2 . 7 2 3 2}$ & $\mathbf{0 . 0 0 0 4}$ \\
Diet * Weight* Time Spent Signalling Before & 0.0531 & 0.8178 \\
Body Size & 0.7157 & 0.3976
\end{tabular}




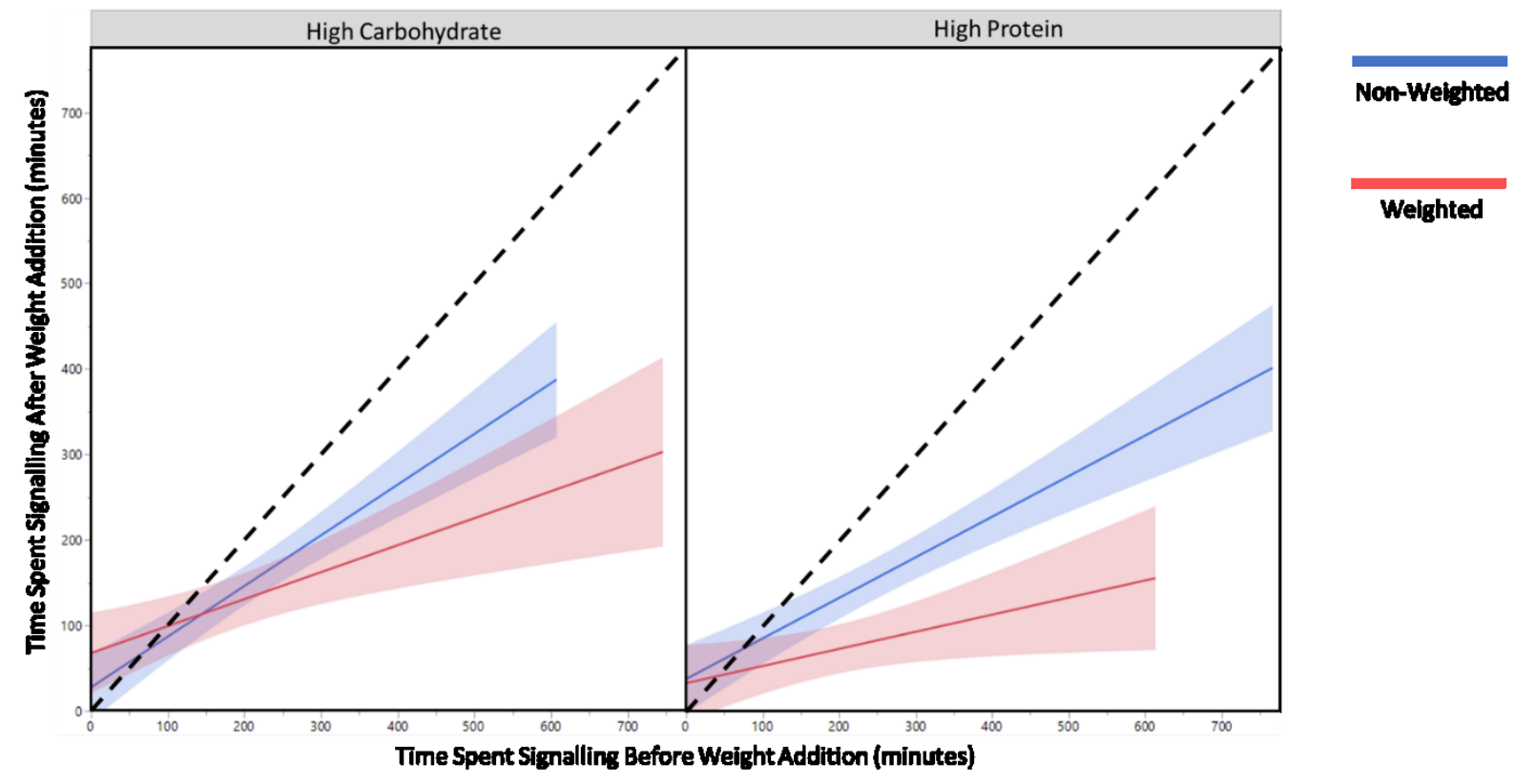

Figure 5: Influence of signalling behaviours before the addition of the weight treatment, diet treatment, and weight treatment on the signalling behaviours after the addition of the weight treatment. 
Males did not alter the composition of their signals over time. Specifically, males did not alter their amplitude (Figure 6) or their carrier frequency (Figure 7). Further, neither the diet nor the weight treatments appeared to impact male amplitude or carrier frequency. 


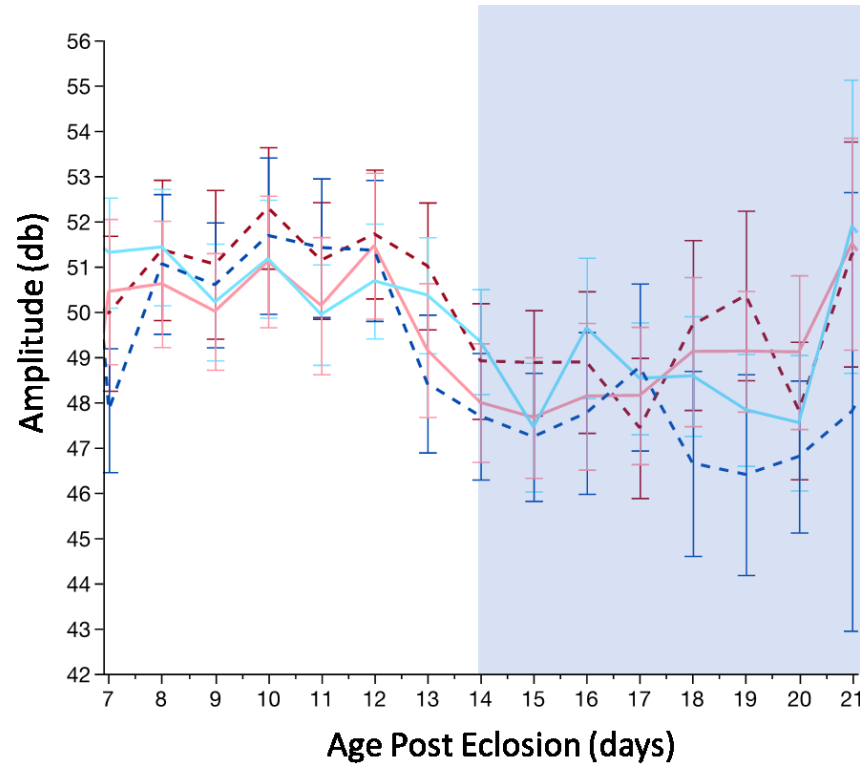
High Carbohydrate Diet Treatment and Non-Weighted Control Treatment

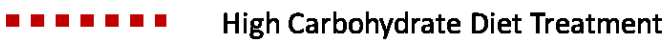
And Weighted Treatment

High Protein Diet Treatment and Non-Weighted Control Treatment

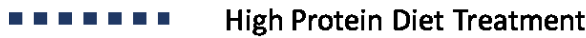
and Weighted Treatment

Figure 6: Fluctuations in amplitude one week before (white) and after (shaded blue) a weight stressor was applied across all treatments. 


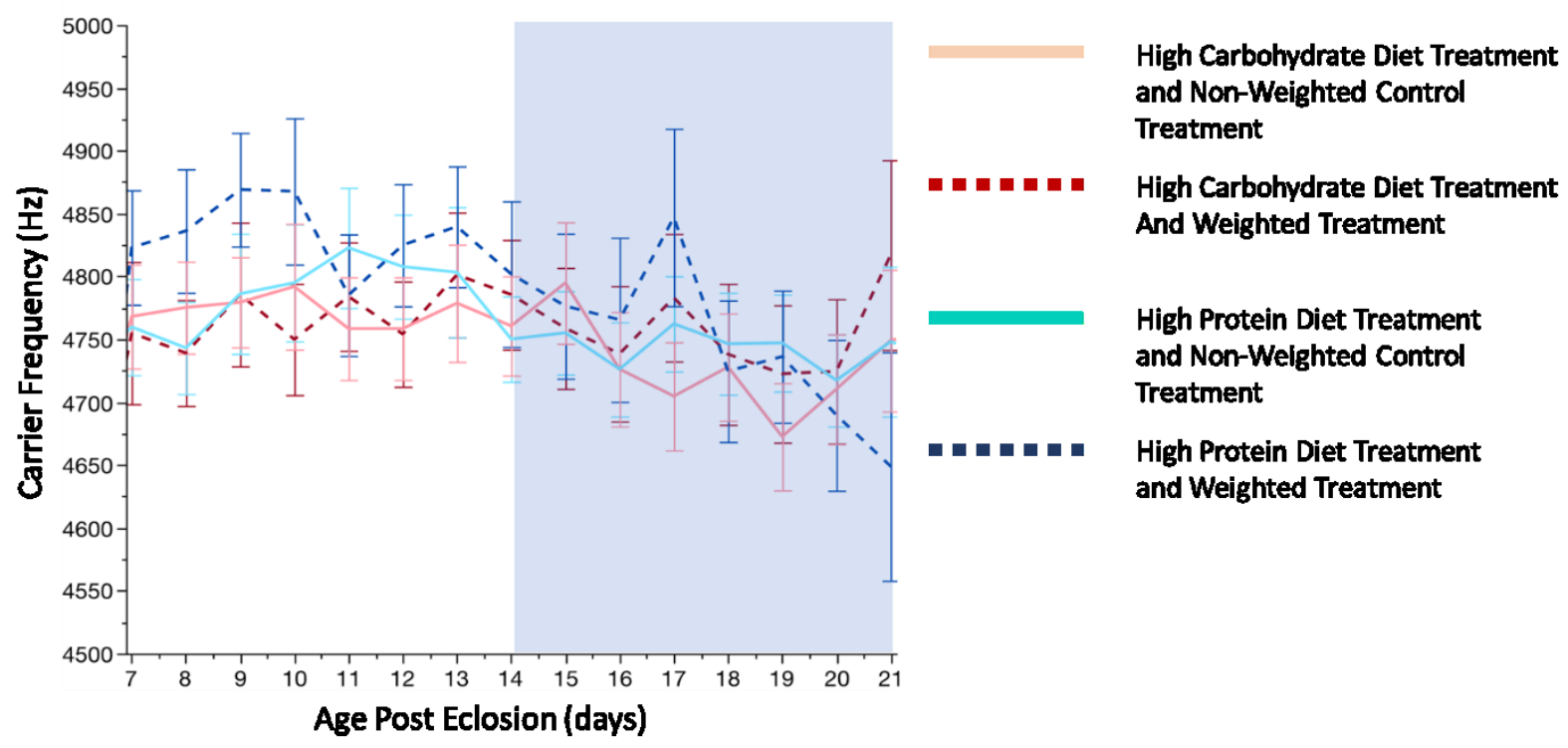

Figure 7: Fluctuations in carrier frequency one week before (white) and after (shaded blue) a weight stressor was applied across all treatments. 
Signalling Factors and Longevity

I ran a factor rotated principle component analysis (PCA) on signalling components that were most indicative of female mate choice. My PCA included carrier frequency, amplitude, chirp rate, and body size. I selected two principle components because they both had eigenvalues that exceeded 1 (Kaiser, 1964). Combined, these two factors explained $73 \%$ of the variance (Table 4). Signalling factor 1 was indicative of overall body size, as individuals with high signalling factor 1 scores were larger, signalled loudly, and at lower carrier frequencies. Signalling factor 2 was indicative of chirp rate and amplitude, as individuals with high signalling factor 2 scores signalled loudly at a high chirp rate. Signalling factor 2 was significantly related to signalling effort ( $\mathrm{df}=220, \mathrm{~F}=116.057, \mathrm{P}<0.001$; Figure 8). Males that signalled with high signal factor 2 scores spent more time signalling. 
Table 4: Rotated principal components depicting fine scale signalling components signalling factors 1 and 2. A negative sign in front of a signalling component is indicative of that component being negatively associated with the related signalling factor.

\begin{tabular}{l|rr} 
Fine Scale Signal Component & Signalling Factor 1 & Signalling Factor 2 \\
\hline Eigenvalue & 1.8195 & 1.1131 \\
Percent & 45.488 & 27.826 \\
Cumulative Percent & 45.488 & 73.314 \\
Body Size & $\mathbf{0 . 8 0 7 4}$ & -0.0189 \\
Amplitude & $\mathbf{0 . 5 8 0 3}$ & $\mathbf{0 . 4 6 7 0}$ \\
Chirp Rate & -0.0193 & $\mathbf{0 . 7 0 8 0}$ \\
Carrier Frequency & $\mathbf{- 0 . 5 0 5 6}$ & -0.0177
\end{tabular}




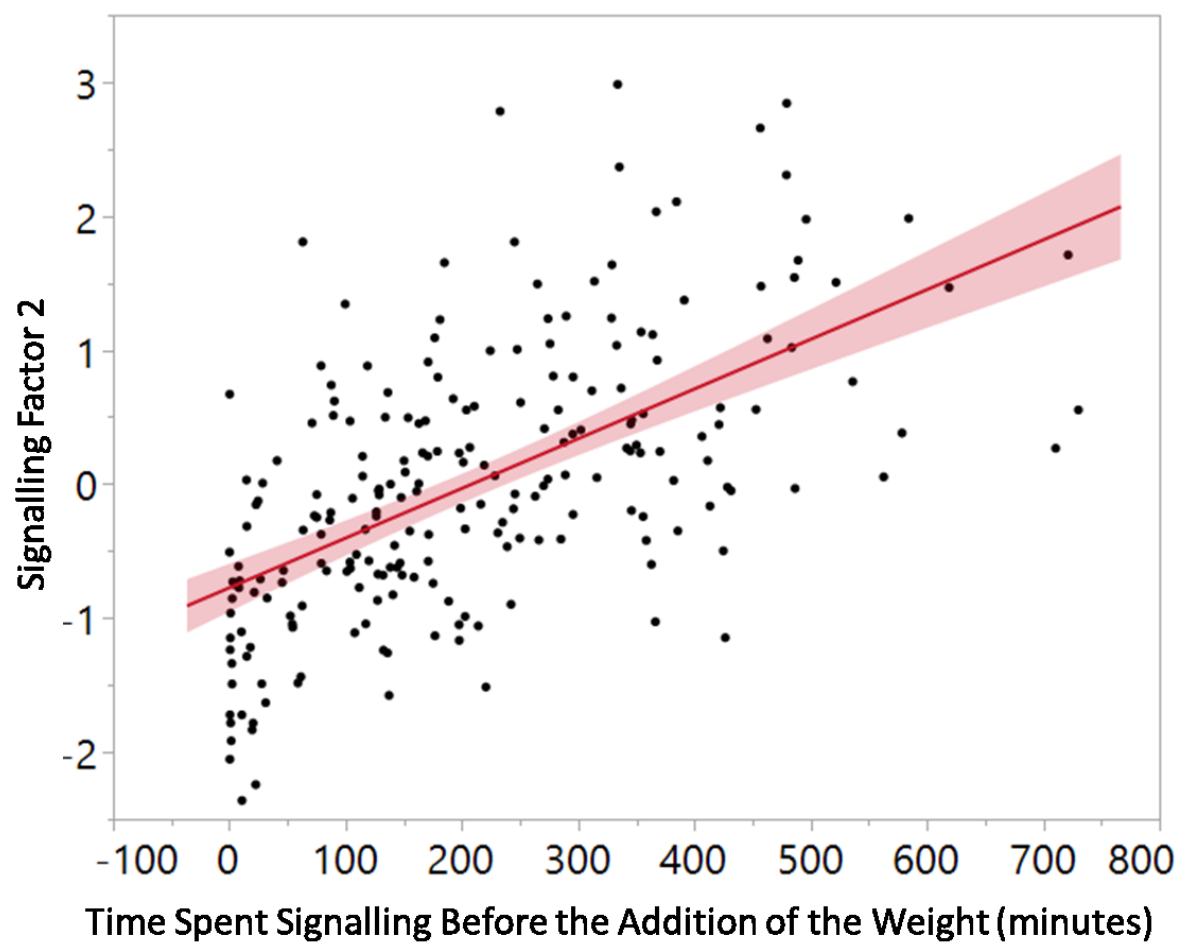

Figure 8: Relationship between the signal factor 2 and time spent calling before the addition of the weight. 
I then investigated whether male survival was predicted by signalling factors 1 or 2 , after accounting for variation due to the diet and weight treatments (Table 5; Figure 9). Male survival was explained by a significant interaction between signalling factor 2, diet, and weight (Table 5). Overall, survival was positively related to signalling factor 2 in all treatments except the control non-weighted treatment on high carbohydrate diet; that treatment shows no relationship between signalling factor 2 and survival (Figure 9). These results suggest that for all males that experienced the added weight or the protein diets (or both), survival was explained by variation in male chirp rate and amplitude, with males that chirped louder and at higher rates living longer. This model also showed that individuals reared on the high carbohydrate diet lived significantly longer than individuals reared on the high protein diet (Table 5; Figure 9). 
Table 5: Kaplain-Meier survival analysis showing how diet and weight stress treatments, signalling factors 1 and 2, and their interactions influence longevity.

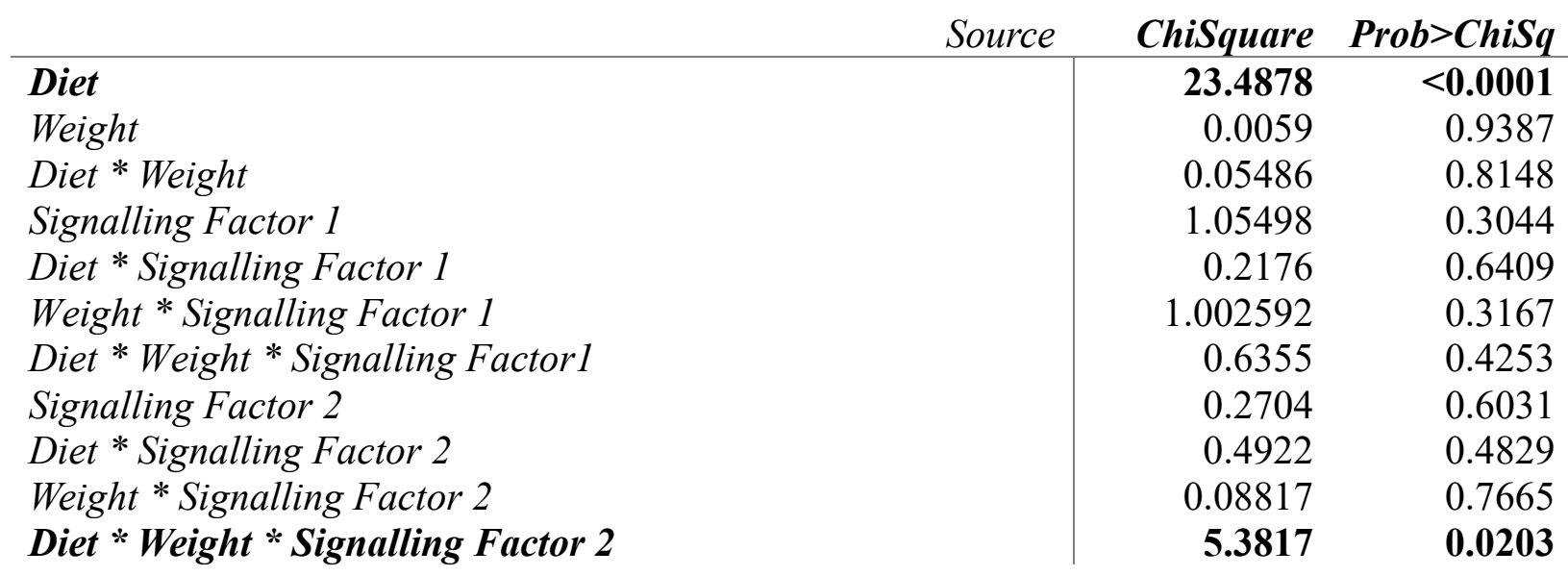




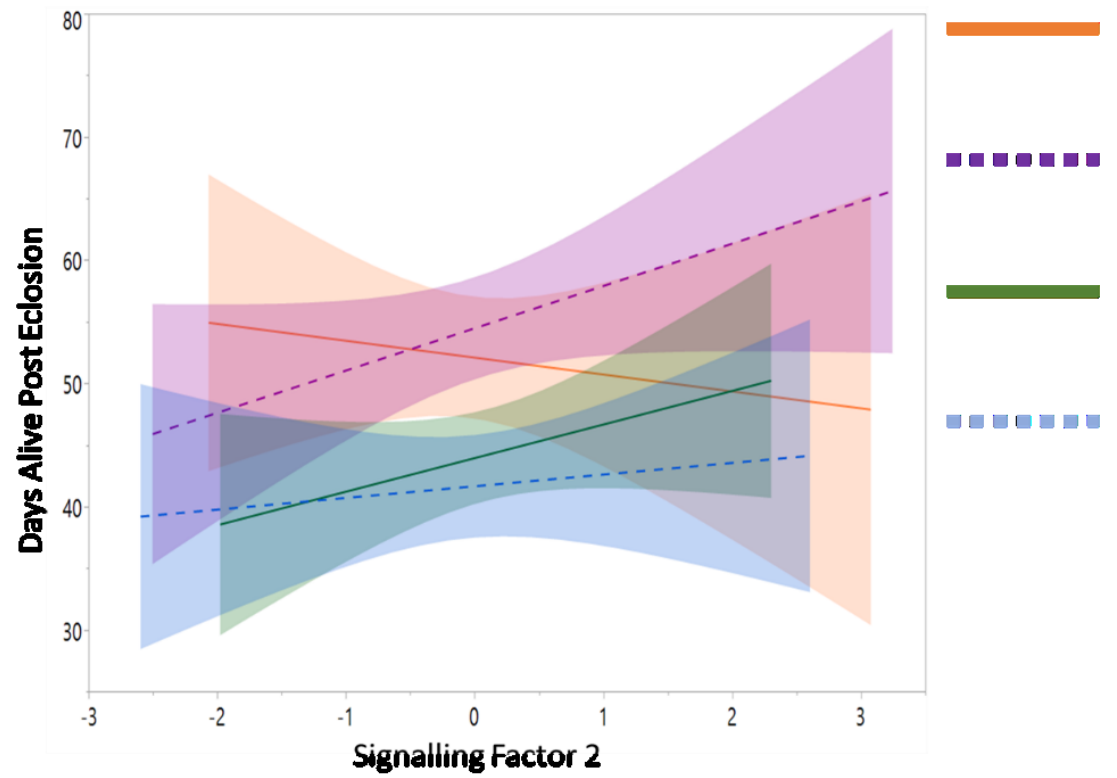

High Carbohydrate Diet Treatment and Non-Weighted Control Treatment

High Carbohydrate Diet Treatment And Weighted Treatment

High Protein Diet Treatment and Non-Weighted Control Treatment

High Protein Diet Treatment and Weighted Treatment

Figure 9: Relationship between signalling factor 2 and survival post eclosion across both diet and weight treatments. 


\section{Females}

Females fed high carbohydrate diets survived significantly longer than females fed high protein diets (Table 6; Figure 10). Specifically, females fed high carbohydrate diets survived on average 56 days, whereas females fed high protein diets survived on average 40 days. The weight treatment did not significantly influence female longevity, although there was a general trend for weighted females to die younger (Figure 10). Longevity was influenced by a three-way interaction between diet treatment, weight treatment, and number of eggs $(\mathrm{df}=1$, Wald ChiSq= 5.975, $\mathrm{P}=0.0145$; Figure 11). This interaction seems to be largely driven by the difference between the high carbohydrate treatment when females were non weighted controls and the other treatments. Survival tended to be negatively influenced by the number of eggs oviposited in all treatments were females were weight stressed and/or fed a high protein diet (Figure 11). However, in the high carbohydrate non weighted treatment, females laid fewer eggs than when they were fed protein diets, but there was a positive relationship between longevity and number of eggs oviposited. 
Table 6: Kaplein-Meier survival analysis using the Walds estimator testing stressors and their interactions on longevity.

\begin{tabular}{l|rr} 
Source & ChiSquare & Prob $>$ ChiSq \\
\hline Diet & $\mathbf{1 1 . 0 6 2 0 7}$ & $\mathbf{0 . 0 0 0 9}$ \\
Weight & 3.3066 & 0.0690 \\
Diet * Weight & 1.8183 & 0.1775 \\
Number of Eggs Oviposited & 1.4904 & 0.2222 \\
Diet * Number of Eggs Oviposited & 0.05625 & 0.8125 \\
Weight * Number of Eggs Oviposited & 1.902 & 0.1678 \\
Diet *Weight * Number of Eggs Oviposited & $\mathbf{5 . 9 7 5 1 5}$ & $\mathbf{0 . 0 1 4 5}$ \\
Body Size & 0.1511 & 0.6975
\end{tabular}



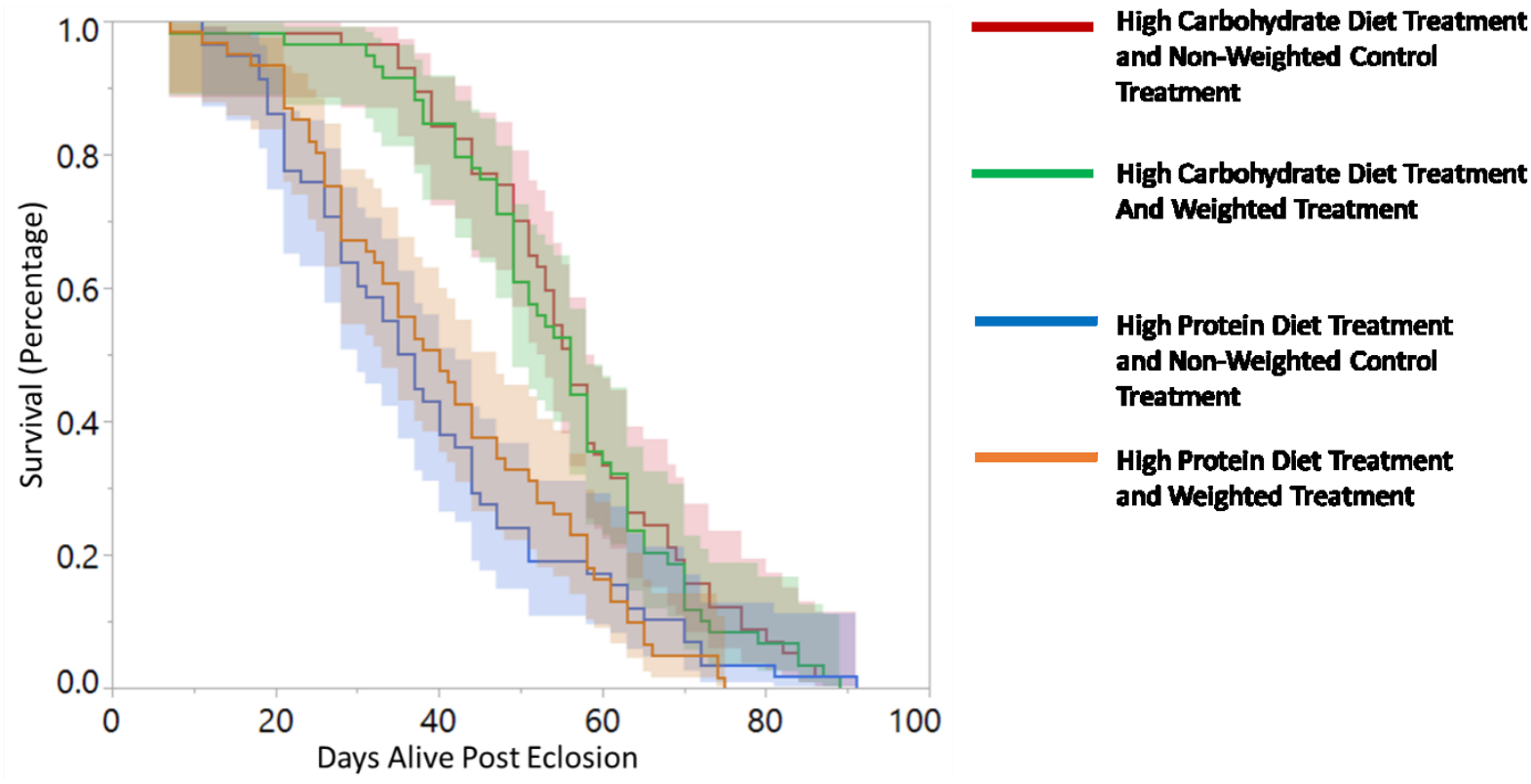

\section{High Protein Diet Treatment and Non-Weighted Control \\ Treatment}

High Protein Diet Treatment and Weighted Treatment

Figure 10: Plotted Kaplain-Meier survival analysis showing the impact of diet and weight stress, across high carbohydrate and high protein diets, on longevity in females. 


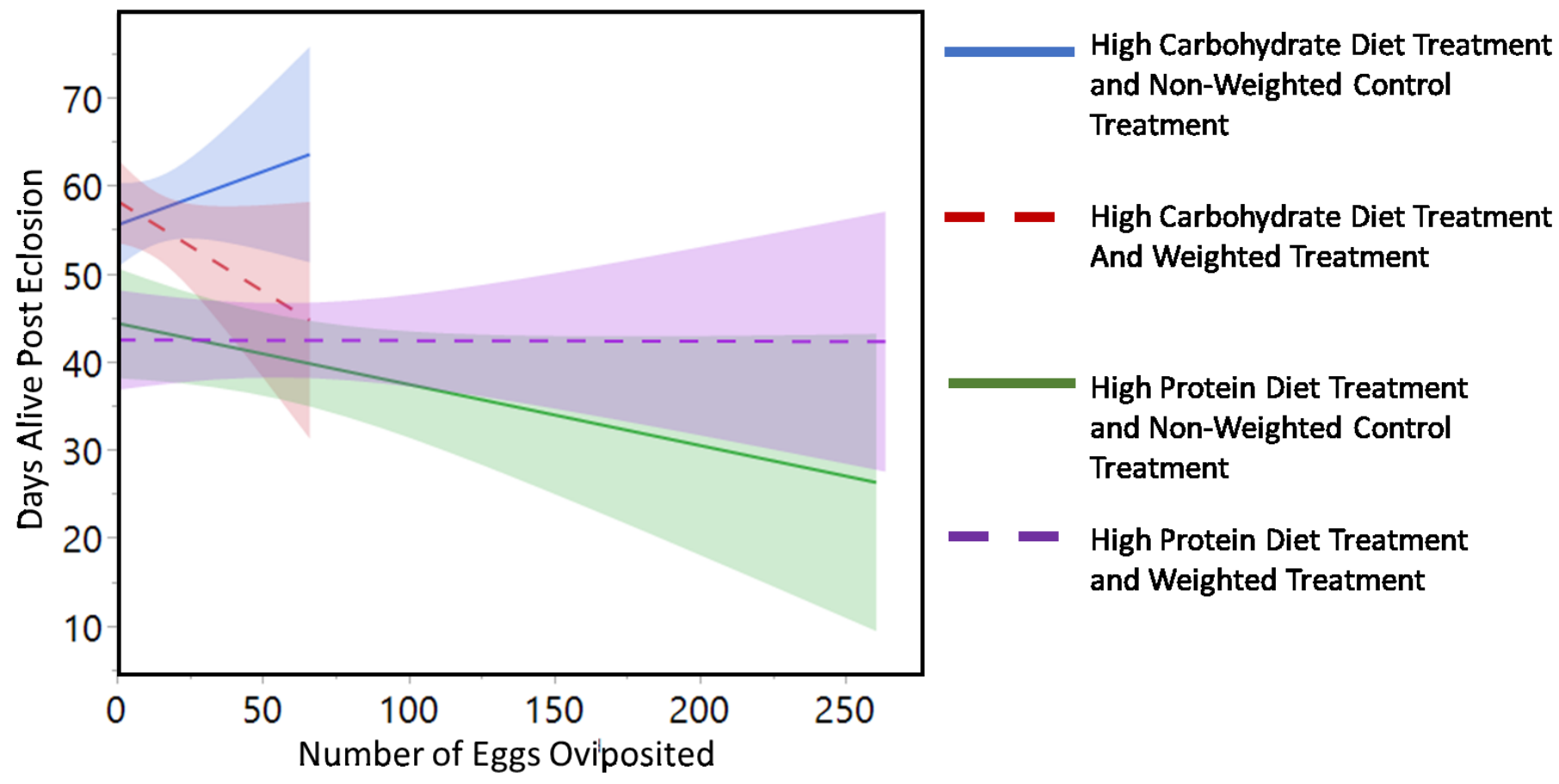

Figure 11: Relationship between the number of eggs an individual oviposited in one week and its impact on longevity across the different weight and diet stress treatments. 


\section{$\underline{\text { Discussion }}$}

Since the first publication of viability-based indicator models, there have been numerous empirical and theoretical tests of these models. Empirical tests often physically manipulated the ornamentation, enhancing or minimizing it, and then quantified the fitness consequences. While these manipulations provide valuable insight into viability-based indicator models, they fail to account for the fitness consequences of correlated life history traits (Cotton, 2016). Further, these manipulations are rarely akin to those that an organism would typically encounter in the wild. As a result, manipulations of this kind might confound experimental findings. To circumvent these concerns, Cotton (2016) performed a novel experimental test of viability-based indicator models. Instead of physically manipulating the ornament of the stalk-eyed fly, for her $\mathrm{PhD}$ thesis Cotton (2016) subjected half the individuals to a weighted manipulation by gluing small weights (pieces of paper) to their backs in order to stress them and to reduce their longevity. She ran complimentary experiments both in the field and in the lab. In females, Cotton saw that there was no relation between relative eye span and survival. In males, however, Cotton saw that the degree of ornamentation influenced their likelihood of survival in weighted but not in unweighted males. Specifically, males with larger eye spans survived longer with the weight manipulation than males with relatively smaller eye spans. Cotton's (2016) thesis shows clear support for viability-based indicator models and the link between ornamentation and survival.

I repeated Cotton's (2016) research using crickets as my model organism. I added a weight that was exactly $20 \%$ of the cricket's body weight and asked whether males that signalled often for mates were better able to survive longer with the added weight than males that signalled less often. Because crickets spend substantially more time walking than flying, I was uncertain whether a weight manipulation would influence survival. I therefore also simultaneously used a 
diet manipulation as a second stressor treatment. I predicted that individuals fed high protein diets would die sooner than individuals fed high carbohydrate diets. To test the viability-based indicator models and the link between ornamentation and survival, I predicted that males who put more effort into signalling should be better able to cope with the manipulations (weight and protein diet) and therefore survive longer than the males in the same treatments who signal less often.

My research supported the hypothesis that males who signalled with higher effort lived longer than those who signalled with lower effort, as I found that longevity was significantly influenced by time spent signalling, regardless of the weight or dietary treatment (Table 2). Male field crickets ( $G$. pennsylvanicus) signal acoustically to attract mates and exhibit extensive, repeatable variation in the amount of time they spend signalling (Harrison et al. 2013). Females listen to signalling males and then acoustically orient to the ones they are most attracted to (Holzer et al. 2003; Scheuber et al. 2003). Evidence suggests that females are more attracted to males that signal most often, for longer durations (increased pulse duration, pulses per chirp, chirp duration), with a lower carrier frequency, with higher amplitudes (Jeffery et al. 2005: Judge, 2011). Given females appear to select on signalling effort, then according to the condition dependent handicap hypothesis, males with high signalling efforts should be in better condition and should survive longer (Zahavi 1975; Zahavi 1977). High effort signallers should be able to survive longer because they should be more capable of bearing the extreme costs associated with their level of ornamentation than low effort signallers. Given I found that longevity was significantly influenced by time spent signalling, my results provides evidence to support the viability-based indicator models. 
Judge et al., (2008) also investigated whether survival was influenced signalling effort male fall field crickets (G. pennsylvanicus). They crudely manipulated diet and quantified longevity and signalling effort (time spent signalling). Similar to my study, Judge et al., (2008) found a positive correlation between male ornamentation and survival, as males that signalled more often survived longer than males that signalled less often (Judge et al. 2008). Also similar to my study, Judge et al., (2008) found that individuals that consumed poor quality diets died sooner than individuals that were fed high quality diets. Combined, these two studies suggest support for viability-based indicator models.

These results are interesting because they show support for condition dependence where the explored trait is plastic and not fixed. For examples, Cotton (2016) showed support for condition dependence using Stalk-eyed flies whose sexually selected trait (eyespan) is fixed. Female field crickets on the other hand select upon the signalling behaviours of males. Male signalling behaviours have been shown to be a plastic trait, meaning that individuals can alter how they are displaying. Male signals can alter through time depending on conditions (both physiologically and temporally).These findings are important because they show that even plastic traits can be used indicators of quality.

\section{Signalling Factors and Their Interactions}

I also found that male survival was influenced by a three-way interaction between diet, weight, and signalling factor 2 (Table 3 ). Overall, survival was positively related to signalling factor 2 in all treatments except the control non-weighted treatment on high carbohydrate diet (Figure 9). This finding provides additional support for the viability-based indicator models, as it reveals that male survival is higher when they signal louder and at a higher chirp rate while experiencing a stressor (additional body weight and/or a high protein diet). Given that signal 
factor 2 also relates positively with signalling effort, females should be able to listen to only a few seconds of the male song use information contained in the song (amplitude and chirp rate) to detect: (1) whether the males signal often, and (2) whether the males will live long when they experience stressful conditions.

The significant interaction between diet, weight, and signal factor 2 was driven by the control males that were fed the high carbohydrate diets. In this treatment, there appeared to be no relationship between survival and signal factor 2 . These crickets experienced fairly pristine conditions as they did not experience a weight stress and were fed a diet that is known to be ideal diet for fuelling both signalling and longevity (Maklakov et al., 2008; Harrison et al., 2014; Thomson et al., 2014; Riefer et al., 2018). This finding of no significant relationship between survival and signalling factor 2 in the benign stress treatment (high carbohydrate diet and no weight stress) aligns perfectly with Cotton et al's (2016) finding that under benign stress conditions (no weight stress) there was no relationship between survival and the size of eye stalks in flies. When conditions are pristine, the relationship between secondary sexual trait elaboration and survival may be hidden or sometimes even negative. The condition dependent handicap hypothesis suggests that highly elaborate males can even have decreased survival if the payoff of elaborate ornamentation is properly accelerated (Höglund and Sheldon, 1998; Eshel et al., 2000; Kokko et al., 2002). Further, the relationships between traits are typically highly sensitive to the environment in which they are measured (Rice, 1988; Ellegren and Sheldon, 2008).

Future research should be focused on the influence signalling behaviours have on lifetime reproductive success. Lifetime reproductive success refers to the total number of offspring an individual's sires over its lifetime and is a common estimate of individual fitness (Clutton-Brock, 
1988). Individuals who are of a higher quality should produce more offspring over the course of their lifetime as compared to lower quality males. Lower quality males should over invest into signalling and reproduction and suffer negative fitness consequences. Simmons (1988) investigated how body size influenced lifetime reproductive success in field crickets $(G$. bimaculatus). Simmons found that smaller males invested more heavily into reproduction. The costs of producing spermatophores was greater for smaller males and that these males spent more time attempting to attach the spermatophores to females once mounted. Females were also found to preferentially select for larger males (Simmons, 1988). Condition dependence should not only influence survival but also lifetime reproductive success. Those males who are of higher quality should be better able to cope with manipulations (either by the addition of weight or through diet) and still have an increased lifetime reproductive success as compared to lower quality males.

\section{Weight Manipulation}

Weight manipulations did not significantly impact survival in either males or females. This finding appears at first to contradict Cotton's (2016) results, as her field and lab studies revealed that the weight manipulation negatively influenced survival in both males and females. It is possible that I did not see a direct impact of the weight manipulation on survival because of the model organism I used. Cotton (2016) used an extremely small organism that spends most of its time flying. Even a relatively small increase in weight should have negatively impacted the individual's ability to fly, limiting its ability to acquire food and evade predators. Cotton's (2016) field research utilized a mark-recapture method to track her experimental individuals, where the stalk-eyed flies were freely able to move around in the jungle, foraging for their own resources, evading predators, and competing in lek mating rituals, all while carrying the 
additional weight. Conversely, I used field crickets (G. pennsylvanicus) in a laboratory setting with small containers, where the crickets did not need to avoid predators, spend time searching for food or water, or flying to new locations. In fact, individuals did not need to expend a great deal of energy doing anything other than body maintenance and calling for mates or ovipositing eggs. Because my experimental individuals did not have to compete for resources and mates and avoid predation events, the additional weight may not have impacted mortality.

Before I ran my MSc experiment, I ran a pilot study that incorporated a variety of weights $(0 \%, 10 \%, 20 \%, 30 \%)$ and observed how these weights influenced cricket behaviour and survival. The $30 \%$ weight seemed to completely over encumber the males and they seemed to experience difficulty moving around. Given this, I thought $30 \%$ was too much weight for the crickets and that it would exaggerate my findings; instead I used a $20 \%$ tailored weight as my extreme. In retrospect, a 20\% weight may not have been enough of a weight difference, given the unchallenging environment that restricted flight.

However, I may not have seen a direct impact of the weight manipulation on survival because the individuals reallocated their resources away from secondary sexual trait elaboration and towards survival. Weight manipulated males in Cotton's stalk-eyed fly study could not reduce the size of their eye span. However, weight manipulated males in my study could reduce their signalling effort. Sure enough, my results revealed that weight manipulated males reduced their time spent signalling significantly more than non weighted controls (Figure 5), with low effort signallers often stopping signalling altogether after the addition of the weight. This finding provides tangential support for the viability-based indicator models in males. Weighted males may have used their energy to build muscle rather than to produce long distance mating signals. Stress responses allow animals to undergo physiological network alterations to better cope with 
challenging conditions (Adamo, 2017). These alterations allow the animals to increase their survival at a cost that results in trade-offs (Adamo 2012). For instance, during times of heightened predation stress, animals often allocate resources to gain a physical boost to evade predators. However; this amplified physical state requires energy. This results in a trade-off of fitness for the resources that come from another physiological network (Hawlena and Schmitz, 2010). Insects are known to adapt their signalling behaviours in response to increased predation stress by modifying their signalling characteristics or stopping to signal entirely (Zuk and Kolluru, 1998), so it should not be surprising that with an added weight stress, my low effort signallers also ceased signalling.

\section{Diet Manipulation}

The variation in condition has been shown to be influenced by genetics (Blanckenhorn and Hosken, 2003) but it's possible to alter this variation of condition through diet manipulations (Hill, 2011). Nutrition can influence expression of secondary sexual traits. High quality diet might positively correlate with trait expression whereas poor quality diets might negatively correlate with trait expression (Harrison etal 2017). Dietary manipulations can increase the variance in condition within a given population which can be useful when examining condition dependence of a plastic trait such as signalling in field crickets. Those males who are in better condition should be able to maintain somatic maintenance and reproductive effort despite these diet manipulations (Zajitschek etal. 2012).

My research showed that diet significantly influenced the survival of field cricket in both males (Tables 2 and 3) and females (Table 5). Specifically, males and females that were fed high carbohydrate diets survived significantly longer than those fed high protein diets. Males fed high carbohydrate diets also signalled for longer periods of time as compared to males fed high 
protein diets. Males therefore maximized both their lifespan and time spent signalling on the high carbohydrate diets, a finding that aligns with previously published research (e.g., Maklakov etal. 2008; Harrison et al. 2014). The degree of sexual ornamentation and nutrition are interwoven, and imbalances can lead to fitness reductions (Morehouse et al. 2010). Resources necessary to produce elaborate traits come from individuals' diets. For instance, ungulates require large quantities of calcium and phosphorus to produce antlers (Lincoln, 1992; Morehouse et al, 2010). Females of the species Blattella germanica, require protein for egg production. For crickets, the carbohydrate diets provide the energy required for prolonged signalling (Thomson et al. 2014). There is an added benefit for G. pennsylvanicus males that signal often as they age, because males gain a fitness advantage as they become older because females prefer older males (Judge, 2011). Signals are costly to produce and are therefore indicative of nutritional status, which females use as an indicator of indirect fitness benefits (Hoback and Wagner, 1997; Scheuber et al. 2003).

A potential problem with diet manipulations are that they don't only influence the variance of sexual traits but can also have physiological costs. For example, Povey (2009) found that varying the levels of carbohydrates and protein can influence immune function. African armyworms who suffered from bacterial infections (Bacillus subtilis) survived longer as they consumed higher proportions of protein. Individuals who consumed more protein showed increased antibacterial activity but showed decreasing phenoloxidase activity, indicating a potential trade-off (Povey etal. 2009). Dietary imbalances have also been linked to decreased lifespan in Drosophila melanogaster (Hatle etal. 2006; Skorupa etal. 2008). Another drawback to my study is the absence of measuring individual caloric intake. Studies have shown that reduced caloric intake has been linked to longer lifespans across many organisms including 
insects (Speakman etal. 2016). Although individuals in my research were fixed upon either a high carbohydrate or high protein diet, individuals might have been able to compensate by simply consuming more. Controlling for caloric intake could have also revealed survival differences.

\section{Factors Influencing Female Survival}

In contrast to males, females exhibited a trade-off between maximizing reproduction and maximizing longevity. Specifically, female survival was influenced by a three-way interaction between the diet manipulation, the weight manipulation, and the number of eggs a female oviposited (Table 5). This significant interaction seemed to be largely driven by non weighted control individuals that were fed high carbohydrate diets. Under this treatment alone, females who oviposited more eggs survived longer. That said, their reproductive success overall was substantially lower than it was when they were fed protein rich diets, regardless of whether they experienced the weight manipulation or not. For all other treatments, the relationship between longevity and egg laying was negative, suggesting that unlike males, there were no super condition females who were capable of both ovipositing lots of eggs and surviving a long time. This finding adds further support to the condition dependent handicap hypothesis, as it suggests females in good condition cannot simultaneously maximize both reproduction and longevity.

In my experiment, females fed the high protein diet oviposited more eggs over the course of their lifetime compared to females fed the high carbohydrate diet. However, the females fed high protein diet also died younger than females fed the high carbohydrate diet. Females can not therefore simultaneously maximize survival and fecundity. This finding aligns with previously published research (Harrison et al. 2014). Females are therefore limited, based on their nutrient uptakes, into where resources will ultimately be allocated (Morehouse et al., 2010) because they 
have a sex specific optimum where they cannot simultaneously maximize all fitness traits at once (Maklakov et al. 2008). When a nutritional imbalance occurs, individuals may end up suffering the costs of reduced fitness (Morehouse et al. 2010).

\section{Conclusion}

Males that signalled more often lived longer when they experienced a weight stress. Further, males that signalled more attractively (high signal factor 2 score) lived longer when they experienced a weight and a diet stress. It appears that the weight stress did not direly impact longevity because males exposed to the weight manipulation reduced their signalling effort, reallocating resources used for signalling towards survival instead. My diet manipulation exposed sex-based fitness trade-offs, as males were able to maximize both their longevity and sexual signalling behaviours on the high carbohydrate diet whereas females exhibited trade-offs, optimizing either their reproduction on high protein diets at the cost of longevity or optimizing their longevity on high carbohydrate diets at the cost of reproduction. Together these findings provide substantial support for the condition-dependent handicap hypothesis. 


\section{References}

Adamo, S. A. (2012). The effects of the stress response on immune function in invertebrates: an evolutionary perspective on an ancient connection. Hormones and Behavior, 62(3), 324-330.

Adamo, S. A. (2017). The stress response and immune system share, borrow, and reconfigure their physiological network elements: evidence from the insects. Hormones and Behavior, 88, 25-30.

Andersson, M. (1982). Female choice selects for extreme tail length in a widowbird. Nature, 299 (5886), 818-820.

Andersson, M. B. (1994). Sexual Selection. Princeton University Press.

Baker, R. H., \& Wilkinson, G. S. (2001). Phylogenetic analysis of sexual dimorphism and eyespan allometry in stalk-eyed flies (Diopsidae). Evolution, 55(7), 1373-1385.

Balmford, A., Jones, I. L., \& Thomas, A. L. (1994). How to compensate for costly sexually selected tails: the origin of sexually dimorphic wings in long-tailed birds. Evolution, 48(4), 1062-1070.

Beckers, O. M., \& Wagner Jr, W. E. (2012). Eavesdropping parasitoids do not cause the evolution of less conspicuous signalling behaviour in a field cricket. Animal behaviour, 84(6), $1457-1462$.

Bertram, S. M., Xochitl Orozco, S., \& Bellani, R. (2004). Temporal shifts in conspicuousness: mate attraction displays of the Texas field cricket, Gryllus texensis. Ethology, 110(12), 963975. 
Bertram, S. M., Whattam, E. M., Visanuvimol, L., Bennett, R., \& Lauzon, C. (2009). Phosphorus availability influences cricket mate attraction displays. Animal Behaviour, 77(2), 525-530.

Blanckenhorn, W. U., \& Hosken, D. J. (2003). Heritability of three condition surrogates in the yellow dung fly. Behavioral Ecology, 14(5), 612-618.

Bonduriansky, R., Maklakov, A., Zajitschek, F., \& Brooks, R. (2008). Sexual selection, sexual conflict and the evolution of ageing and life span. Functional Ecology, 22(3), 443-453.

Buchanan, K. L., \& Evans, M. R. (2000). The effect of tail streamer length on aerodynamic performance in the barn swallow. Behavioral Ecology, 11(2), 228-238.

Burkhardt, D., \& De la Motte, I. (1985). Selective pressures, variability, and sexual dimorphism in stalk-eyed flies (Diopsidae). Naturwissenschaften, 72(4), 204-206.

Cabrera-Guzmán, E., Crossland, M. R., Brown, G. P., \& Shine, R. (2013). Larger body size at metamorphosis enhances survival, growth and performance of young cane toads (Rhinella marina). PLoS One, 8(7), e70121.

Carmona, D. M., Menalled, F. D., \& Landis, D. A. (1999). Gryllus pennsylvanicus (Orthoptera: Gryllidae): laboratory weed seed predation and within field activity-density. Journal of Economic Entomology, 92(4), 825-829.

Carranza, J., \& Pérez-Barbería, F. J. (2007). Sexual selection and senescence: male sizedimorphic ungulates evolved relatively smaller molars than females. The American Naturalist, 170(3), 370-380.

Cotton A.J. (2016). What drives sexual selection? Meiotic drive, stress and mate choice in stalkeyed flies. PhD Thesis. University College London. London England. 
Cotton, S., Fowler, K., \& Pomiankowski, A. (2004). Do sexual ornaments demonstrate heightened condition-dependent expression as predicted by the handicap hypothesis? Proceedings of the Royal Society of London. Series B: Biological Sciences, 271(1541), 771-783.

Cotton, S., Small, J., \& Pomiankowski, A. (2006). Sexual selection and condition-dependent mate preferences. Current Biology, 16(17), R755-R765.

Clutton-Brock, T. H. (1988). Reproductive success: studies of individual variation in contrasting breeding systems. University of Chicago Press.

Criddle, N. (1925). Field crickets in Manitoba. The Canadian Entomologist, 57(4), 79-84.

Darwin, C. (1859). The Origin of Species. John Murray. London.

Darwin, C. (1871). The Descent of Man and Selection in Relation to Sex. John Murray. London.

Ellegren, H., \& Sheldon, B. C. (2008). Genetic basis of fitness differences in natural populations. Nature, 452(7184), 169.

Eshel, I., Volovik, I., \& Sansone, E. (2000). On Fisher-Zahavi’s handicapped sexy son. Evolutionary Ecology Research, 2(4), 509-523.

Falconer D.S., and Mackay T.F.C. 1996. Introduction to Quantitative Genetics (fourth edition). Edinburgh Gate, Harlow, England. Pearson Education Limited.

Ferguson. G.L. (2018). How developmental and behavioural plasticity in the fall field cricket is influenced by the acoustic social environment and anthropogenic noise. PhD Thesis. Carleton University. Ottawa Canada.

Fisher, R. A. (1915). The evolution of sexual preference. The Eugenics Review, 7(3), 184. 
Fisher, R.A. (1930). The Genetical Theory of Natural Selection. Oxford. Clarendon Press.

French, B. W., \& Cade, W. H. (1989). Sexual selection at varying population densities in male field crickets, Gryllus veletis and G. pennsylvanicus. Journal of Insect Behavior, 2(1), 105121.

Gangwere, S. K. (1961). A monograph on food selection in Orthoptera. Transactions of the American Entomological Society (1890-), 87(2/3), 67-230.

Grafen, A. (1990). Biological signals as handicaps. Journal of Theoretical Biology, 144(4), 517546.

Harrison, S. J., Godin, J. G. J., \& Bertram, S. M. (2017). Influence of dietary nutrient balance on aggression and signalling in male field crickets. Animal Behaviour, 134, 123-134.

Harrison, S. J., Raubenheimer, D., Simpson, S. J., Godin, J. G. J., \& Bertram, S. M. (2014). Towards a synthesis of frameworks in nutritional ecology: interacting effects of protein, carbohydrate and phosphorus on field cricket fitness. Proceedings of the Royal Society of London B: Biological Sciences, 281(1792), 20140539.

Harrison, S. J., Thomson, I. R., Grant, C. M., \& Bertram, S. M. (2013). Calling, courtship, and condition in the fall field cricket, Gryllus pennsylvanicus. PloS one, 8(3), e60356.

Hatle, J. D., Wells, S. M., Fuller, L. E., Allen, I. C., Gordy, L. J., Melnyk, S., \& Quattrochi, J. (2006). Calorie restriction and late-onset calorie restriction extend lifespan but do not alter protein storage in female grasshoppers. Mechanisms of ageing and development, 127(12), 883-891. 
Hawlena, D., \& Schmitz, O. J. (2010). Physiological stress as a fundamental mechanism linking predation to ecosystem functioning. The American Naturalist, 176(5), 537-556.

Hill, G. E. (2011). Condition-dependent traits as signals of the functionality of vital cellular processes. Ecology Letters, 14(7), 625-634.

Hoback, W. W., \& Wagner, W. E. Jr. (1997). The energetic cost of calling in the variable field cricket, Gryllus lineaticeps. Physiological Entomology, 22(3), 286-290.

Höglund, J., \& Sheldon, B. C. (1998). The cost of reproduction and sexual selection. Oikos, $83: 478-483$.

Holzer, B., Jacot, A., \& Brinkhof, M. W. (2003). Condition-dependent signaling affects male sexual attractiveness in field crickets, Gryllus campestris. Behavioral Ecology, 14(3), 353359.

Hunt, J., Brooks, R., Jennions, M. D., Smith, M. J., Bentsen, C. L., \& Bussiere, L. F. (2004). High-quality male field crickets invest heavily in sexual display but die young. Nature, 432(7020), 1024.

Iwasa, Y., \& Pomiankowski, A. (1994). The evolution of mate preferences for multiple sexual ornaments. Evolution, 48(3), 853-867.

Iwasa, Y., \& Pomiankowski, A. (1999). Good parent and good genes models of handicap evolution. Journal of Theoretical Biology, 200(1), 97-109.

Jeffery, J., Navia, B., Atkins, G., \& Stout, J. (2005). Selective processing of calling songs by auditory interneurons in the female cricket, Gryllus pennsylvanicus: possible roles in 
behavior. Journal of Experimental Zoology Part A: Ecological Genetics and Physiology, 303(5), 377-392.

Joern, A., \& Behmer, S. T. (1997). Importance of dietary nitrogen and carbohydrates to survival, growth, and reproduction in adults of the grasshopper Ageneotettix deorum (Orthoptera: Acrididae). Oecologia, 112(2), 201-208.

Johnstone, R. A., \& Grafen, A. (1993). Dishonesty and the handicap principle. Animal Behaviour, 46(4), 759-764.

Judge, K. A. (2011). Do male field crickets, Gryllus pennsylvanicus, signal their age? Animal Behaviour, 81(1), 185-194.

Judge, K. A., Ting, J. J., \& Gwynne, D. T. (2008). Condition dependence of male life span and calling effort in a field cricket. Evolution, 62(4), 868-878.

Kaiser, H. F. (1964). A method for determining eigenvalues. Journal of the Society for Industrial and Applied Mathematics, 12(1), 238-248.

Kokko, H. (1998). Good genes, old age and life-history trade-offs. Evolutionary Ecology, 12(6), 739-750.

Kokko, H., Brooks, R., McNamara, J. M., \& Houston, A. I. (2002). The sexual selection continuum. Proceedings of the Royal Society of London. Series B: Biological Sciences, 269(1498), 1331-1340.

Kotiaho, J. S., LeBas, N. R., Puurtinen, M., \& Tomkins, J. L. (2008). On the resolution of the lek paradox. Trends in Ecology \& Evolution, 23(1), 1-3.

Lincoln, G. A. (1992). Biology of antlers. Journal of Zoology, 226(3), 517-528. 
Maklakov, A. A., Simpson, S. J., Zajitschek, F., Hall, M. D., Dessmann, J., Clissold, F., Raubenheimer D., Bonduriansky R., \& Brooks, R. C. (2008). Sex-specific fitness effects of nutrient intake on reproduction and lifespan. Current Biology, 18(14), 1062-1066.

Møller, A. P. (1989). Viability costs of male tail ornaments in a swallow. Nature, 339(6220), $132-135$.

Morehouse, N. I., Nakazawa, T., Booher, C. M., Jeyasingh, P. D., \& Hall, M. D. (2010). Sex in a material world: why the study of sexual reproduction and sex-specific traits should become more nutritionally-explicit. Oikos, 119(5), 766-778.

Mowles, S. L. (2014). The physiological cost of courtship: field cricket song results in anaerobic metabolism. Animal behaviour, 89, 39-43.

Pomiankowski, A. (1988). The Evolution of Female Mating Preferences for Male Genetic Quality. Oxford University Press, USA.

Povey, S., Cotter, S. C., Simpson, S. J., Lee, K. P., \& Wilson, K. (2009). Can the protein costs of bacterial resistance be offset by altered feeding behaviour?. Journal of Animal Ecology, 78(2), $437-446$.

Reifer, M. L., Harrison, S. J., \& Bertram, S. M. (2018). How dietary protein and carbohydrate influence field cricket development, size and mate attraction signalling. Animal Behaviour, 139, 137-146.

Rice, W. R. (1988). Heritable variation in fitness as a prerequisite for adaptive female choice: the effect of mutation-selection balance. Evolution, 42(4), 817-820. 
Roberts, J. A., Taylor, P. W., \& Uetz, G. W. (2006). Consequences of complex signaling: predator detection of multimodal cues. Behavioral Ecology, 18(1), 236-240.

Robinson, M. R., Pilkington, J. G., Clutton-Brock, T. H., Pemberton, J. M., \& Kruuk, L. E. (2006). y, die young: trade-offs between fitness components and sexually antagonistic selection on weaponry in Soay sheep. Evolution, 60(10), 2168-2181.

Rowe, L., \& Houle, D. (1996). The lek paradox and the capture of genetic variance by condition dependent traits. Proceedings of the Royal Society of London B: Biological Sciences, 263(1375), 1415-1421.

Scheuber, H., Jacot, A., \& Brinkhof, M. W. (2003). Condition dependence of a multicomponent sexual signal in the field cricket Gryllus campestris. Animal Behaviour, 65(4), 721-727.

Scheuber, H., Jacot, A., \& Brinkhof, M. W. (2003). The effect of past condition on a multicomponent sexual signal. Proceedings of the Royal Society of London B: Biological Sciences, 270(1526), 1779-1784.

Simmons, L. W. (1988). Male size, mating potential and lifetime reproductive success in the field cricket, Gryllus bimaculatus (De Geer). Animal Behaviour, 36(2), 372-379.

Skorupa, D. A., Dervisefendic, A., Zwiener, J., \& Pletcher, S. D. (2008). Dietary composition specifies consumption, obesity, and lifespan in Drosophila melanogaster. Aging cell, 7(4), $478-490$.

Speakman, J. R., Mitchell, S. E., \& Mazidi, M. (2016). Calories or protein? The effect of dietary restriction on lifespan in rodents is explained by calories alone. Experimental gerontology, 86 , 28-38. 
Sterner, R. W., \& Elser, J. J. (2002). Ecological stoichiometry: the biology of elements from molecules to the biosphere. Princeton University Press.

Thomson, I. R., Darveau, C. A., \& Bertram, S. M. (2014). Body morphology, energy stores, and muscle enzyme activity explain cricket acoustic mate attraction signaling variation. PloS one, 9(3), e90409.

Travers, L. M., Garcia-Gonzalez, F., \& Simmons, L. W. (2015). Live fast die young life history in females: evolutionary trade-off between early life mating and lifespan in female Drosophila melanogaster. Scientific Reports, 5, 15469.

Trivers, R. (1972). Parental Investment and Sexual Selection. (Vol. 136, p. 179). Cambridge, MA: Biological Laboratories, Harvard University.

Vinogradov, A. E. (1998). Male reproductive strategy and decreased longevity. Acta biotheoretica, 46(2), 157-160.

Wheeler, D. (1996). The role of nourishment in oogenesis. Annual Review of Entomology, 41(1), 407-431.

Zahavi, A. (1975). Mate selection—a selection for a handicap. Journal of theoretical Biology, 53(1), 205-214.

Zahavi, A. (1977). The cost of honesty: further remarks on the handicap principle. Journal of Theoretical Biology, 67(3), 603-605.

Zajitschek, F., Lailvaux, S. P., Dessmann, J., \& Brooks, R. (2012). Diet, sex, and death in field crickets. Ecology and evolution, 2(7), 1627-1636. 
Zuk, M., \& Kolluru, G. R. (1998). Exploitation of sexual signals by predators and parasitoids. The Quarterly Review of Biology, 73(4), 415-438. 